STORYTELLING AS A FUNDAMENTAL FORM OF ACTING 


\title{
STORYTELLING AS A FUNDAMENTAL FORM OF ACTING
}

\author{
By KIRANDEEP MATHARU, B.Sc.
}

A Thesis Submitted to the School of Graduate Studies in Partial Fulfilment of the Requirements for the Degree Master of Science

McMaster University (C) Copyright by Kirandeep Matharu, June 2019 
McMaster University MASTER OF SCIENCE (2019) Hamilton, Ontario (Psychology, Neuroscience \& Behaviour)

TITLE: Storytelling as a Fundamental Form of Acting

AUTHOR: Kirandeep Matharu, B.Sc. (McMaster University)

SUPERVISOR: Professor S. Brown

NUMBER OF PAGES: $x i, 47$ 


\section{Lay Abstract}

Acting is a process of pretending to be someone who the actor is not. It is often thought of as a skill of trained professionals. We propose that oral storytelling is a form of everyday acting. When a storyteller reads aloud, they act out the characters of the story during moments of dialogue-when the characters themselves are speaking in the story. We explored the vocal portrayal of contrastive characters by both trained actors and non-actors as they read fairy tales aloud. The results revealed that participants, regardless of acting experience, portrayed the characters as predicted, performed the characters uniquely from each other, and remained consistent in their portrayal across a story. Actors were found to use a larger pitch range than non-actors, specifically for high-pitched characters. We argue that portraying characters during storytelling is one of the most fundamental forms of acting in human life. 


\begin{abstract}
Acting is a process of pretending to be someone who the actor is not. While acting is often considered to be a specialized skill of trained professionals, a simple and perhaps universal form of acting occurs during oral storytelling, in which the storyteller acts out the characters of the story during the moments of dialogue and self-reflection. In order to examine this skill experimentally, we had both trained actors and untrained novices read four fairy tales aloud. The stories contained a series of contrastive characters that spanned age, gender, and species. The major dependent variables were the vocal parameters of pitch height, loudness, timbre, and speech rate. The results demonstrated that participants created distinguishable acoustic profiles for each character within a story, regardless of the story's familiarity. Monotonic trend analyses revealed the sequential changes in vocal parameters that were produced as a function of the age, gender, and species of the represented characters. Linear mixed-effects models showed a significant effect of acting training on character portrayal, with actors showing more-expansive pitch depictions than novices. We argue that portraying characters during storytelling is one of the most fundamental forms of acting in human life.
\end{abstract}




\section{Acknowledgements}

I would like to first and foremost thank Dr. Steven Brown for his guidance, support, and passion towards this research. Your experience and knowledge are a great asset to all the work in the NeuroArts lab, but it is your passion for your field that is the life blood. Your unwavering love for your work has been an inspiration.

Thank you to Matthew Berry, who has been like an older brother to me in the lab. With you, I found both an academic mentor and a best friend. I will always be grateful to Onkar Marway for introducing us. Without Onkar, I don't know if I would have become a part of this department, much less this research.

Next, l'd like to thank my colleague and friend Carmen Tu for our wonderful chats. You made working in the lab brighter and lighter.

To my parents, you have always pushed me to go further. You both have worked tirelessly to make sure that your children have all the opportunities you could provide for them. More than that though, you taught me to value myself in a man's world. I love you both.

Lastly, I am thankful to my partner Aaron Bruinsma for his support. You have been there for everything. You supported me through my education: my celebrations, my downfalls, along with multiple essays and reports. You've kept me afloat and encouraged me when I needed an extra push. Most importantly though, you have always been my best friend. 


\section{Table of Contents}

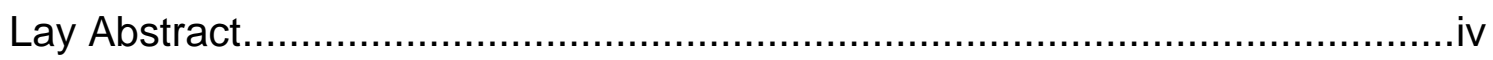

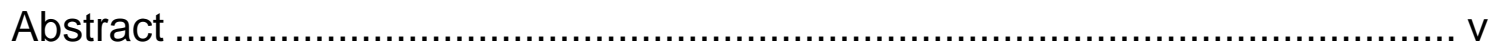

Acknowledgements ............................................................................

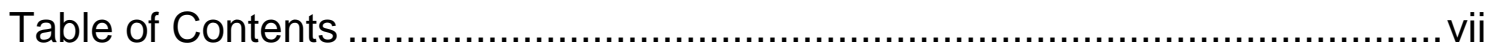

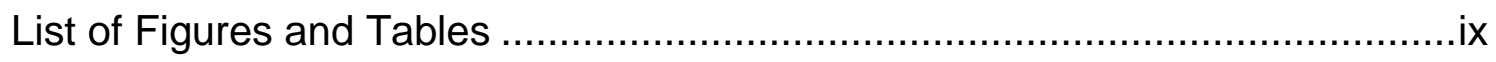

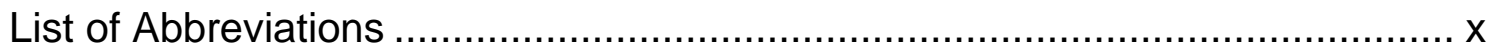

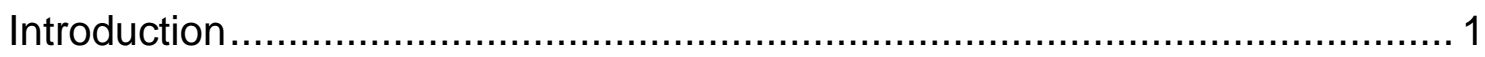

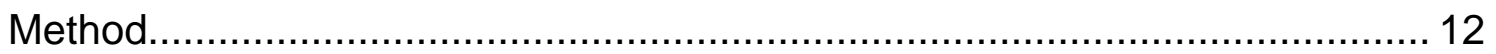

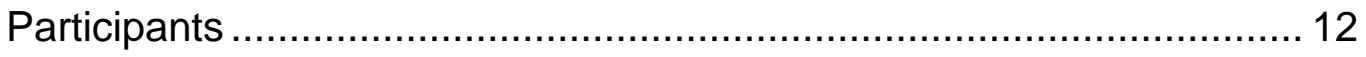

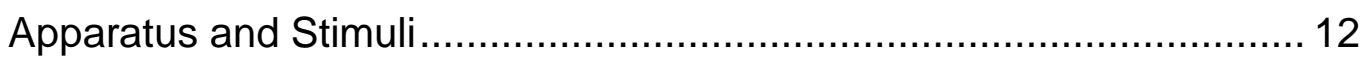

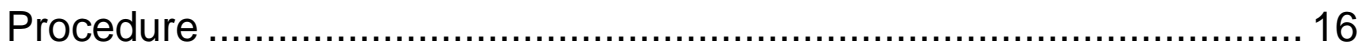

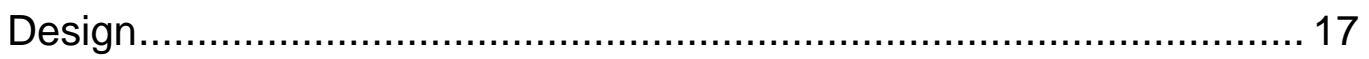

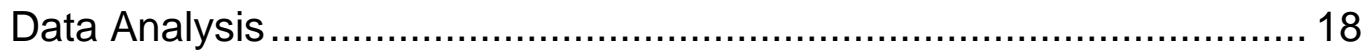

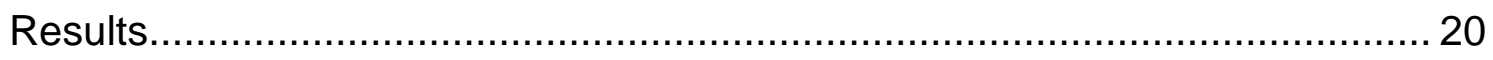

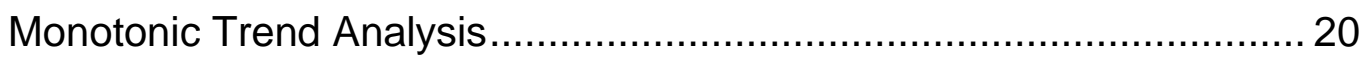

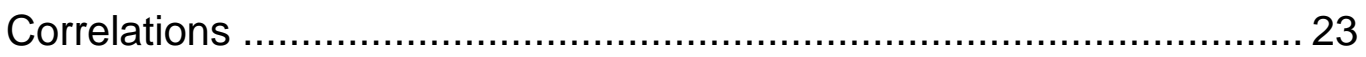

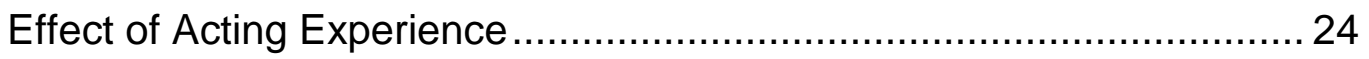

Effects of Participant Gender and Character Gender.......................... 29

Pitch Production Across the Stories .................................................. 30

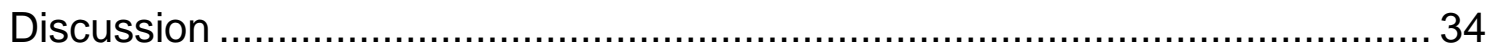

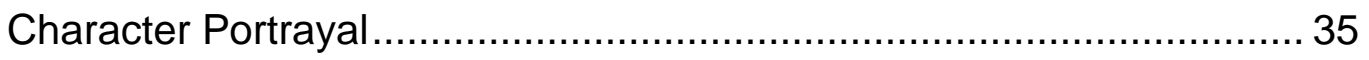




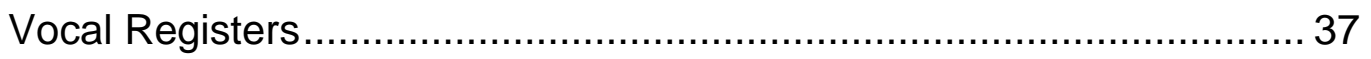

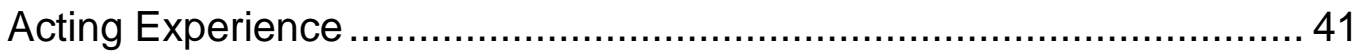

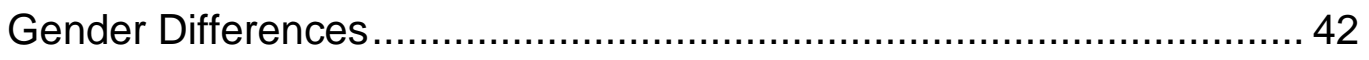

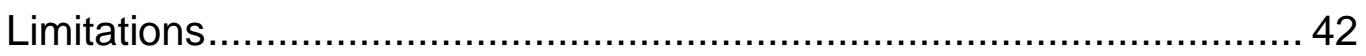

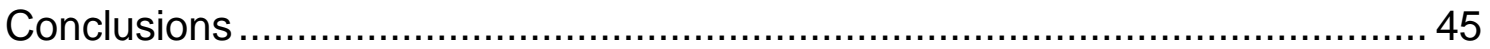

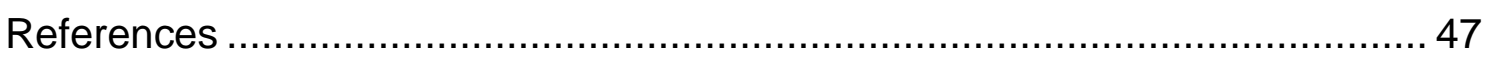




\section{List of Figures and Tables}

Figure 1: Mean Pitch Values for Every Character Across All Four Stories,

Ordered from Lowest to Highest Predicted Pitch ................................. 22

Figure 2: Mean Pitch Values for Every Character Within Each of the Four

Stories, Ordered from Lowest to Highest Predicted Pitch ...................... 23

Figure 3: Mean Pitch as a Function of Acting Experience Across All

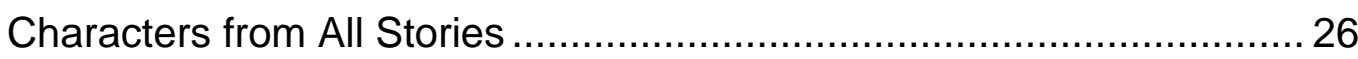

Figure 4: Mean Pitch as a Function of Acting Experience for Each

of the Four Stories

Figure 5: Effect of Acting Experience and Character on Mean Speech

Rate Across All Characters from All Stories.......................................... 29

Figure 6: Mean Pitch Timeline Graphs for the Two Participant Groups

for Goldilocks and the Three Bears and Jack and the Beanstalk........... 32

Figure 7: Mean Pitch Timeline Graphs for the Two Participant Groups

for Little Red Riding Hood and Rose Red .......................................... 33

Figure 8: A Schematic of the Pitch Results for the Non-Actors

And Actors

Table 1: Fairy Tales and Their Characters

Table 2: Ordering of All Characters Across All Four Stories Based

on Age Gender or Species.

Table 3: Correlations Between the Four Vocal Parameters 


\section{List of All Abbreviations}

GTB: Goldilocks and the Three Bears

JB: Jack and the Beanstalk

LRRH: Little Red Riding Hood

RR: Rose Red

LME: Linear Mixed-Effects 


\section{Declaration of Academic Achievement}

The original research presented in this thesis was developed by myself in collaboration with my supervisor Dr. Steven Brown with input from our colleague Matthew Berry. I conducted the participant recruitment, development of stimuli, data collection, data cleaning, and data analysis for this work. The design of this study was conducted in conjunction with Dr. Steven Brown and Matthew Berry. The statistical analyses for this research were completed with guidance from Matthew Berry. The work presented here is in preparation to be submitted for publication in a journal as a paper. 
M.Sc. Thesis - K. Matharu; McMaster University - Psychology, Neuroscience \& Behaviour

\section{Introduction}

In The Republic, Plato (380 BCE/1968) argued that there are three basic forms of narrative, namely diegesis, mimesis, and their combination. In diegesis, a story is told using the voice of a narrator. In mimesis, a story is told using the voice of characters, as seen in the portrayal of characters by theatrical and cinematic actors. Finally, in combined forms of narrative, diegesis and mimesis alternate with one another, such as in the recitation of Homeric epics in Plato's day. During such combined recitations, sections of narration using the narrator's voice are interleaved with segments of dialogue in which characters speak to one another, a format that is nearly universal in novels and children's stories. An effective storyteller of such combined forms of narrative has the task of distinctly portraying all of the characters in the story, as well as differentiating these characters from the voice of the narrator, such as when a parent reads a bedtime story to a child. This process of transient character portrayal—referred to as "proto-acting" (Brown, 2017) — has been proposed as being a precursor to the full-fledged acting of the dramatic actor. Compared to a dramatic actor-who typically portrays a single character over a several-hour performance-a storyteller has to portray multiple contrastive characters, often in quick alternation. These characters can span not only gender and age group, but also species. This is demonstrated in well-known children's stories about three bears, three little pigs, or even a big bad wolf. A good storyteller therefore has to be a good actor as well. In the present study, we explore the idea that the portrayal of characters during oral storytelling is perhaps the most 
M.Sc. Thesis - K. Matharu; McMaster University - Psychology, Neuroscience \& Behaviour

fundamental and universal form of acting in human life. In particular, we examine if a storyteller differentiates the multiple characters of a story with their voice based on the characters' age, gender, and species.

Storytelling can be compared with two other forms of proto-acting, namely impressionism and ventriloquism. The impressionist portrays multiple characters, but typically does so with little or no dialogue between characters. By contrast, a ventriloquist engages in constant dialogue between herself and her dummy character-requiring a constant modulation of her manner of speaking—but only for a single character. Oral storytelling combines the need to portray multiple contrastive characters found in impressionism with the need for dialogue between characters found in ventriloquism. Hence, this complex form of proto-acting demands a skilled performance from the storyteller, whether that be a professional storyteller or a parent reading a bedtime story to his child. In the present study, we explored the recitation of fairy tales as a means of addressing these phenomena.

Previous work on the portrayal of individuals, real or fictional, has provided qualitative information, but has often lacked quantitative prosodic details. Character portrayal in the literature can be grouped into three categories: the portrayal of fictional characters during oral reading, the portrayal of fictional characters during conversation, and the portrayal of real individuals during quotation in conversation. A very sparse set of studies has investigated the vocal and/or gestural portrayal of fictional characters during story reading. Doukhan et al. (2011) had a single male actor read 12 children's tales aloud and measured the 
M.Sc. Thesis - K. Matharu; McMaster University - Psychology, Neuroscience \& Behaviour

vocal properties of the storytelling in order to develop a text-to-speech (TTS) system. The actor portrayed a total of 27 characters across the 12 stories, who varied in age, gender, and kind/species (Doukhan et al., 2011), a categorization method that the authors would use in later studies (Doukhan et al., 2012, 2015). Although these characters were categorized, no predictive scheme was presented for the vocal portrayal of the characters. After a preliminary vocal analysis, the characters were grouped into nine categories (four female and five male) of prototypical characters using a post hoc hierarchical cluster analysis. The vocal dependent variables included pitch, pitch variability, pitch range, loudness, loudness variability, and devoiced vowels. These variables were measured during dialogue, when the characters spoke in a story. Although Doukhan et al. (2011) recorded many variables, they did not report the results for all of them for each character. Rather, only the most relevant variables were reported for the nine prototypical characters. The results showed that the youngest characters had the highest pitch and greatest loudness (but girls had the lowest loudness), and all adult characters, regardless of gender, had comparable mean pitch and intensity. A drawback of using this study to exemplify the vocal characteristics of character portrayal is that its primary aim was to develop a TTS system, rather than to analyze character portrayal. However, this study provides some insight into the vocal portrayal of fictional characters during oral story reading.

Montano et al. (2013), similar to Doukhan et al. (2011), examined character portrayal during story reading as a means of developing a TTS system. Similar to 
M.Sc. Thesis - K. Matharu; McMaster University - Psychology, Neuroscience \& Behaviour

the earlier study, the authors looked at only a single professional storyteller. However, unlike it, they looked at only a single character, namely Harry Potter from the novel Harry Potter and the Philosopher's Stone, and they only focused on the vocal measurement of pitch. Since the measures included the spoken lines of only one character(rather than a dialogue between two characters), the lines were categorized by emotion, rather than by character. These included the basic emotions of hot anger, cold anger, joy, sadness, surprise, and fear. Compared to the control condition of neutral emotion, almost all of the basic emotions were spoken with a slower speech rate, higher pitch, and greater loudness. Sadness was the only emotion that showed a lower pitch and reduced loudness. Fear displayed a speech rate similar to neutral speech. The storyteller, without being prompted, imitated the prepubescent voice of Harry Potter.

In the more naturalistic context of pretend play, children are well known to depict characters, both real and fictional, although these studies also lack quantitative details. In an analysis of the existing literature at the time, Bretherton (1989) proposed that children assume the roles of both playwright and actor when conveying stories during pretense. As playwrights, children make decisions about the plot, role distribution, and props to create the desired scene, sometimes during the course of the scene itself. As actors, children understand the concept of portraying an individual outside of themselves, whether fictional or real. For example, a child may portray a father character using either their own body or a human-like toy as a surrogate. To portray these characters, children use their face, 
M.Sc. Thesis - K. Matharu; McMaster University - Psychology, Neuroscience \& Behaviour

gestures, and voice. For example, they may use a wailing voice when portraying a character who is crying. Sawyer (1996) analyzed the pretend-play behaviors of 24 preschool children in a naturalistic observational study. During pretend play, children portrayed characters by creating appropriate dialogue for the scene to depict the characters' emotions. They not only voiced the characters who they embodied, but they also created voices for inanimate objects, such as toys. Children modified the prosody, lexicon, and pragmatics of their speech when depicting a character, but he did not quantitatively measure any vocal parameters in his observational study. Finally, Cohen (2011) studied preschool children in an observational study of pretend play. As with Sawyer (1996), she found examples of children modifying their voice when portraying characters. For example, when portraying adult female characters, the children used a higher-pitched voice, especially when the characters were excited. Overall, the studies mentioned thus far demonstrate general qualitative features of character portrayal, but do not provide quantitative details about contrastive portrayals across the dramatis personae of a single story or bout of pretend play.

Before discussing the quotation of real people during conversation as a form of personal portrayal, we will mention the interesting example of fictional character portrayal that occurs during everyday conversation. When someone sees a film and wants to recount the story to a friend, they may quote one or more of the film's characters during a particular scene by portraying these characters. Bavelas et al. (2014) carried out a study in which participants recounted a short scene from the 
M.Sc. Thesis - K. Matharu; McMaster University - Psychology, Neuroscience \& Behaviour

2004 movie Shrek 2 after having just viewed the scene. Both body gesturing and vocal changes were examined. The tendency to portray a character when describing the scene occurred more often when the participants told the story to another person, compared to when they were talking on their own, arguing that such character portrayal serves as a form of demonstration (Clark, 2016). For example, one participant portrayed a scene from the film in which the large ogre picked up the cat with two fingers and held the cat in front of his face. The participant used facial expressions to imitate the menacing expression of the ogre and the fearful, apologetic look of the cat, used a hand gesture with two fingers to mime the ogre picking up the cat, and used their voice to produce a direct quotation of the fearful cat from the film. The authors' focus was to account for conversational demonstrations in general, and thus they did not quantify the specific acoustic vocal changes made during character portrayal. This study showed that character portrayal by everyday individuals does occur in a naturalistic setting.

In a study that looked at the quotation of both fictional characters and real individuals, Blackwell, Perlman, \& Tree (2015) transcribed the depictions used when participants described eighteen short YouTube clips to a confederate. The clips contained humans, non-human animals, and personified inanimate objectsboth fictional characters and real individuals. The authors found that direct quotations showed a greater number of vocal and bodily demonstrations than did non-direct quotations. During these depictions, participants changed the pitch of their voice to portray the people, animals, and/or things within the videos. For 
M.Sc. Thesis - K. Matharu; McMaster University - Psychology, Neuroscience \& Behaviour

example, a little girl was portrayed using a high pitch, while a dog was portrayed using a low-pitched howl. Because the purpose of this study was to explore the presence of both vocal and bodily portrayals during direct or indirect quotations, it did not report a detailed vocal analysis of the produced portrayals. Wade \& Clark (1993) studied direct quotations after having participants watch various scenes of videotaped dialogue only one time and then retelling them to a listener. In principle, reported speech can be introduced in two ways: direct quotation ("He said 'wait for me'”) or indirect quotation (he told me to wait). The authors hypothesized that verbatim direct quotations would be unlikely. The mean percentage of verbatim words used for indirect and direct quotations was 35\% and 38\% respectively, and so most of the retellings were not verbatim. Listeners did not equate speaker's accuracy of a narrative with the accuracy of the quotations. Wade and Clark proposed that the lack of verbatim retelling in reported quotation is due to the fact that speakers are more likely to depict how a person speaks than what they say. For example, a participant using direct quotations may depict the sarcasm of a character using the pitch and tone of their voice without reproducing their words verbatim. Just as with previous studies, Wade and Clark also did not provide prosodic details of any portrayal.

A final context in which people portray others is when quoting them during everyday conversations. However, unlike the examples just presented, where people portray fictional characters, here they portray real people, such as friends or public figures like celebrities or politicians. Staging theory (Clark, 2016) 
M.Sc. Thesis - K. Matharu; McMaster University - Psychology, Neuroscience \& Behaviour

proposes that speakers spontaneously depict events for interlocutors using their voice, gestures, and facial expressions. These depictions occur during storytelling when speakers "stage" the events of the story, whether real or fictional. There are different forms of depictions. Our focus in the present study is on embedded depictions, which use direct quotations or reported speech to re-enact a real or possible conversation that occurred at a different time. It is during these direct quotations that we expect that the characters of the story should be depicted and that proto-acting will occur. Stec et al. $(2015,2016,2017)$ analyzed the personal semi-spontaneous narratives of speakers, and annotated the various depictions that occur during quoted speech. These depictions, including character intonation, are proposed to help portray the individuals quoted by the speaker, whether that be themselves or another individual. Stec et al. (2015) found that intonation was used more frequently than manual gestures to portray a person. Specifically, $55.3 \%$ of all quotations employed character intonation, as compared to $20.4 \%$ using manual gestures. As with the previous studies exploring quotation or character portrayal, Stec et al. (2015) mentioned the existence of vocal modulation when participants portrayed another individual, but did not quantify it, merely listing it as being present or absent, since it was only one of several depictions that were measured. Overall, the literature on vocal character portrayal is limited by the fact that it does not provide quantitative detail about how speakers portray characters during storytelling. Because of these limitations, we can look to the large literature on the vocal expression of basic emotions for insights into the most relevant 
M.Sc. Thesis - K. Matharu; McMaster University - Psychology, Neuroscience \& Behaviour

dependent variables for the current study on vocal prosody. Juslin and Laukka (2003), in a meta-analysis of 104 studies using five emotion categories (anger, fear, happiness, sadness, and love-tenderness), found that anger and happiness had increased speech rate, loudness, loudness variability, high-frequency energy (voice quality), mean pitch, and mean pitch variability. In contrast, sadness and tenderness showed decreased speech rate, loudness, loudness variability, high frequency energy, mean pitch, and mean pitch variability. Using the literature on the vocal portrayal of basic emotions and the limited literature on character portrayal, we opted in the present study to use pitch, loudness, timbre, and speech rate as our dependent variables, with an emphasis on pitch.

In addition to the within-subject variable of character, we also set out to examine the between-subject variable of acting experience by comparing trained actors with novices when portraying fictional characters. Since actors have extensive training in the portrayal of individuals, actors should show more exaggerated portrayals than non-actors. While studies comparing actors and nonactors have not examined character portrayal thus far, a handful of studies have examined emotion portrayal. These studies, both laboratory and corpus analyses, have shown that the portrayals of basic emotions by non-actors tend to be appraised by raters as being more realistic and/or authentic than portrayals by trained actors (Anikin et al, 2018; Jurgens et al, 2015; Krahmer \& Swerts 2008; Laukka \& Banzinger, 2018). This might suggest that actors exaggerate their portrayals of emotions compared to non-actors. Jurgens et al (2015) acoustically 
M.Sc. Thesis - K. Matharu; McMaster University - Psychology, Neuroscience \& Behaviour

compared authentic speech recordings (obtained from a database of radio station interviews) to sentences read aloud by both actors and non-actors for the emotions of anger, fear, sadness, and happiness. Both the actors and the non-actors showed a more variable pitch profile compared to the authentic recordings. In addition, the actors showed unique differences with respect to their articulation (i.e., lower amplitude ratio, higher peak frequency, and wider bandwidth of the first formant), most likely due to their vocal training. Anikin et al. (2018) acoustically compared seven corpora of authentic/spontaneous emotion vocalizations with acted-out versions. The vocalizations were short sounds representing the emotions of achievement, amusement, anger, disgust, fear, and pleasure. In contrast to the results of Jurgens et al. (2015), these authors found that authentic sounds included higher pitch, more-variable pitch, less-variable spectral slope, less-variable amplitude, lower harmonicity, and more irregular temporal structure. This difference in results may be due to the fact that this study used short, non-verbal sounds, as compared to the use of full sentences by Jurgens et al. (2015). Since our study used fairy tales as stimuli, the stimuli consisted of full sentences. Finally, a small number of studies have investigated character portrayal by actors in feature films. Recorded portrayals of homosexual characters (Cartei \& Reby, 2012) and Japanese anime characters (Teshigawara \& Murano, 2004) have examined how actors portray characters. Male actors performed homosexual male characters with a high-pitched, female-like voice, in comparison to heterosexual male characters (Cartei \& Reby, 2012). In Teshigawara \& Murano (2004), the performances of 
M.Sc. Thesis - K. Matharu; McMaster University - Psychology, Neuroscience \& Behaviour

anime heroes and villains by a female student were shown to be distinct from one another, as shown by unique changes in the vocal apparatus of the actress.

The principal objective of the present study was to examine the recitation of fairy tales as a fundamental form of acting, one that combines the impressionist's art of individually portraying multiple contrastive characters with the ventriloquist's art of undergoing regular alternation between characters and thus rapid and frequent vocal modification. We carried out the study with the aim of comparing two separate cohorts of participants, namely trained actors and untrained novices to determine how proto-acting may differ among individuals trained in character portrayal and those who are not. Participants read four fairy tales aloud while being audio-recorded. We extracted the passages of narration as well as the sections of dialogue for each character from each story. We analyzed these passages for the prosodic variables of pitch, loudness, timbre, and speech rate. For each of the four stories, we created a predictive pitch scheme based on the gender, age, and species of the characters. For example, we predicted that female characters would speak with higher pitch than male characters, and that juvenile characters would speak with higher pitch than adult characters. We tested out such predictions using a monotonic trend analysis. If the trend analysis was shown to be statistically significant, it would suggest that participants did indeed modulate the pitch of their voice in the manner predicted by our a priori scheme. Next, we used linear mixedeffects models to compare the actors and the novices in between-group analyses. We predicted that both groups would show the same overall pitch trends, but that 
M.Sc. Thesis - K. Matharu; McMaster University - Psychology, Neuroscience \& Behaviour

actors would demonstrate an exaggerated vocal profile compared to novices, most likely by expanding the pitch range used to portray characters. This would be in keeping with the observation that actors tend to exaggerate their prosody compared to non-actors. We also predicted that actors would show a greater consistency in their pitch profiles for individual characters over the full course of a story, whereas novices would be more variable, such that a given character's pitch might be different between the beginning and end of a story. Finally, we performed an exploratory gender analysis to examine the influence of participant gender on depictions of character gender, as well as whether this relationship interacted with acting experience.

\section{Methods}

\section{Participants}

Twenty undergraduate students (mean age $19.9+/-2.7$, age range 18-30) and 20 professional actors (mean age $43.3+/-13.3$, age range $27-63$, mean years of acting experience $22.7+/-12.3$, acting experience range $4-53$ years) participated in this study. The undergraduates received course credit for their participation, while the actors received monetary compensation. The experiment was approved by the McMaster University Research Ethics Board.

\section{Apparatus and Stimuli}

Apparatus. The experiment was conducted in a sound-attenuated room. Participants wore a head-mounted microphone connected to a Blue Icicle interface that recorded their audio into Adobe Audition (Adobe Systems Incorporated, San 
M.Sc. Thesis - K. Matharu; McMaster University - Psychology, Neuroscience \& Behaviour

Jose) on a desktop computer, whose monitor was turned off to reduce participant distraction. An experimenter monitored participants through a desk-mounted webcam that was connected to a computer outside of the sound-attenuated room.

Stimuli. The story stimuli were presented to participants in a binder. Four classic fairy tales were used as stimuli: Goldilocks and the Three Bears (GTB), Jack and the Beanstalk (JB), Little Red Riding Hood (LRRH), and Rose Red (RR). The first three were chosen due to participant familiarity with the narratives and characters, while the last one was chosen to test for proto-acting with an unfamiliar story. During the story-selection process, various fairy tales were compiled from online and print sources (Foreman, 2005; Fujikawa, 2008; Gool, 1993; Guenther, 2015; "The Story of Goldilocks and the Three Bears", 2016). Stories containing at least two male and two female characters were considered, while stories containing numerous minor characters (e.g., the two step-sisters in Cinderella) were excluded from consideration. For each story, the following information was recorded for each character: age, gender, species, number of dialogue sequences, and the average length of the dialogue sequence in words (see Table 1). A sequence of dialogue consisted of the text contained within a single set of quotation marks; this could contain one or more sentences. 
M.Sc. Thesis - K. Matharu; McMaster University - Psychology, Neuroscience \& Behaviour

\begin{tabular}{|c|c|c|c|c|c|c|c|c|c|}
\hline 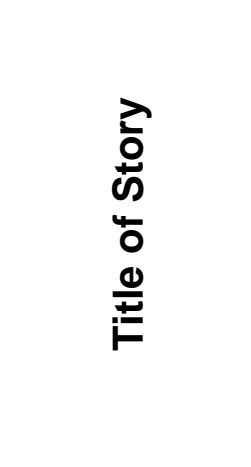 & $\begin{array}{l}\frac{1}{ \pm} \\
\frac{\pi}{0} \\
\frac{\pi}{\pi} \\
\frac{\pi}{0}\end{array}$ & 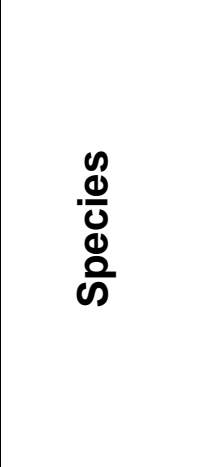 & 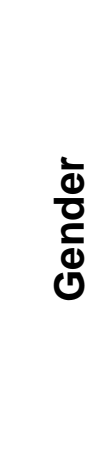 & 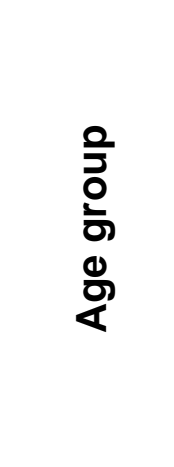 & 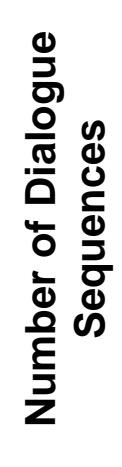 & 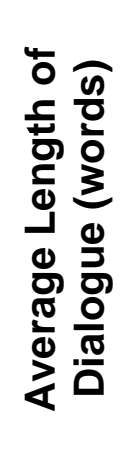 & 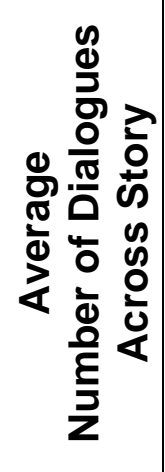 & 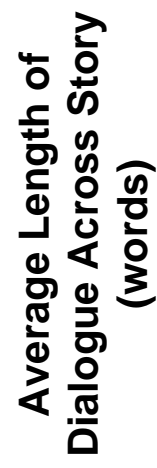 & 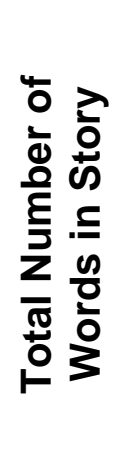 \\
\hline \multirow{4}{*}{$\begin{array}{l}\text { Goldilocks } \\
\text { and the } \\
\text { Three Bears }\end{array}$} & Father Bear & Bear & $\bar{M}$ & Adult & 5 & 6.2 & \multirow{4}{*}{5.8} & \multirow{4}{*}{8.6} & \multirow{4}{*}{693} \\
\hline & Mother Bear & Bear & $\mathrm{F}$ & Adult & 5 & 7.6 & & & \\
\hline & Goldilocks & Human & $\mathrm{F}$ & Child & 9 & 10.1 & & & \\
\hline & Baby Bear & Bear & M & Toddler & 4 & 9.5 & & & \\
\hline \multirow{5}{*}{$\begin{array}{l}\text { Jack and } \\
\text { the } \\
\text { Beanstalk }\end{array}$} & Giant & Giant & $\mathrm{M}$ & Adult & 7 & 6.0 & \multirow{5}{*}{5} & \multirow{5}{*}{10.9} & \multirow{5}{*}{996} \\
\hline & Strange Man & $\begin{array}{l}\text { Human } \\
\text { (mystical) }\end{array}$ & $\mathrm{M}$ & Adult & 2 & 12.5 & & & \\
\hline & Jack & Human & M & Child & 6 & 15.3 & & & \\
\hline & Giant's Wife & Giant & $\mathrm{F}$ & Adult & 5 & 9.6 & & & \\
\hline & Mother & Human & $\mathrm{F}$ & Adult & 5 & 13.0 & & & \\
\hline \multirow{5}{*}{$\begin{array}{c}\text { Little Red } \\
\text { Riding Hood }\end{array}$} & Wolf & Wolf & $\mathrm{M}$ & Adult & 5 & 15.0 & \multirow{5}{*}{4.7} & \multirow{5}{*}{11.5} & \multirow{5}{*}{979} \\
\hline & Woodsman & Human & $M$ & Adult & 3 & 9.3 & & & \\
\hline & $\begin{array}{l}\text { Wolf as } \\
\text { Grandmother }\end{array}$ & $\begin{array}{l}\text { Wolf as } \\
\text { Human }\end{array}$ & $\begin{array}{l}\mathrm{M} \\
\text { as } \mathrm{F}\end{array}$ & Adult & 4 & 9.5 & & & \\
\hline & $\begin{array}{l}\text { Little Red } \\
\text { Riding Hood }\end{array}$ & Human & $\mathrm{F}$ & Child & 7 & 9.0 & & & \\
\hline & Grandmother & Human & $\mathrm{F}$ & Senior & 3 & 11.7 & & & \\
\hline \multirow{5}{*}{ Rose Red } & Bear & Bear & $\mathrm{M}$ & Adult & 5 & 11.4 & \multirow{5}{*}{4.8} & \multirow{5}{*}{13.3} & \multirow{5}{*}{981} \\
\hline & $\begin{array}{l}\text { Bear as } \\
\text { Prince }\end{array}$ & Human & $\mathrm{M}$ & Adult & 3 & 22.7 & & & \\
\hline & Mother & Human & $\mathrm{F}$ & Adult & 4 & 13.0 & & & \\
\hline & Rose Red & Human & $\mathrm{F}$ & Teen & 6 & 8.8 & & & \\
\hline & Little Girl & $\begin{array}{l}\text { Witch/ } \\
\text { mystical } \\
\text { human }\end{array}$ & $F$ & Child & 6 & 14.7 & & & \\
\hline
\end{tabular}

Table 1. Fairy tales and their characters. Characters (excluding the narrator) are listed in ascending order with regard to their predicted vocal pitch after the story-editing process. 
M.Sc. Thesis - K. Matharu; McMaster University - Psychology, Neuroscience \& Behaviour

After selecting specific fairy tales, we edited each one as follows. Each character was given approximately the same number of dialogue sequences, modulated by how regularly the character appeared in the narrative. Each story averaged approximately five dialogue sequences per character. Characters with less than two dialogue sequences were kept in the story but were omitted from the analysis. None of the dialogue sequences were interrupted by narration. For example, the following sentence was not acceptable: "This porridge is too hot," said Goldilocks, "I don't want this!" For every story, the sequences of dialogue across each character were made to average approximately 10 words per sequence. Rhyming sentences of dialogue were eliminated in order to avoid possible pitch effects. Each story was reduced to run approximately five minutes in length at a normal speed of recitation, or an average of 900 words per story. Table 1 contains all character information, dialogue averages across the stories, and relative character pitch predictions for each story, ordered top to bottom from lowest pitch to highest pitch after the story-editing process. The characters were organized in a hierarchy based on age and gender as follows: adult (male), adult (female), child (male), senior (female), child (female), toddler. This was further broken down by species, where a bear, for example, would speak with a lower pitch than a wolf. In addition to sections of character speech, each fairy tale was comprised primarily of passages of narration, which were subject to analysis (see below). Lastly, participants read the standard "Rainbow Passage" (Fairbanks, 1960) to establish a baseline of their conversational pitch. 
M.Sc. Thesis - K. Matharu; McMaster University - Psychology, Neuroscience \& Behaviour

\section{Procedure}

Participants were given the fairy tale stimuli, experimental instructions, and a questionnaire several days prior to the experiment. They were able to complete the questionnaire online. The questionnaire inquired about native language, childhood reading habits, current reading habits, and experience reading to others. Upon arrival to the lab, participants provided their consent, and completed the questionnaire in person if they had not already done so online. The experimental instructions were repeated to ensure clarity. Participants were then escorted to a soundproof room to complete some vocal warm-up tasks and then the experiment. Participants were instructed to read expressively as if reading the story to a child. If they misread a sentence, they were instructed to reread the sentence from the beginning, rather than continue to the end of the sentence. The recitations were done at a self-directed pace.

During the warm-up phase, habitual speaking pitch was measured by calculating the mean vocal pitch during the recitation of the standard "Rainbow Passage" (Fairbanks, 1960). As a practice for working with dialogue, participants were asked to read aloud the short story Jerry's New Sled (Jackson, 1969) in an expressive manner, as if they were reading to a child, but this portrayal was not measured. After completion of the warm-up phase, the experimenter left the soundproof room, and the participant began the experiment. A fairy tale was first read aloud as practice. The same fairy tale was then read again as a test trial. Only 
M.Sc. Thesis - K. Matharu; McMaster University - Psychology, Neuroscience \& Behaviour

test trials were analyzed. This process was repeated for all four fairy tale stimuli, whose order of presentation was randomized.

\section{Design}

While the experiment utilized a mixed-model design in which all participants read all of the stories, the stories were analyzed independently of one another in four separate analyses. There were four independent variables: character, character gender, acting experience, and participant gender. Character and character gender were within-subject variables, whereas acting experience and participant gender were between-subject variables. The levels of character corresponded with the series of characters in each story (see Table 1). In addition to the characters, the narrator was included as a voice distinct from the participants' conversational voice. The number and length of narrator lines chosen for the analysis were matched to the average number and length of character lines within each story. For the narrator lines, the first line and last line of each story were chosen, as well as three approximately equally spaced lines from the middle of the story. Chosen narrator lines were required to not have character dialogue directly precede or follow them. Most stories had an average of five sequences of dialogue per character. The average length of character dialogue for all four stories was 11 words. Next, the independent variable of acting experience consisted of two groups: actors and non-actors. Lastly, gender was comprised of both the gender of the characters within the story and the gender of the participants. 
M.Sc. Thesis - K. Matharu; McMaster University - Psychology, Neuroscience \& Behaviour

\section{Data Analysis}

Each participant's audio file was divided into individual sentences of dialogue or narration using Adobe Premiere Pro CC (Adobe Systems Incorporated, San Jose). Acoustic analyses were carried out using Praat software (Boersma, 2001). An in-house script trimmed all audio files to strictly include only vocalized parts. All sections of silence and noise were eliminated using a two-pass filter derived from Hirst (2011), except in calculating the durational values for speech rate. After the audio was trimmed, another Praat script analyzed various parameters of each spliced audio file, including duration (seconds), pitch (hertz), loudness (decibels), and timbre (harmonics-to-noise ratio, HNR). Duration was used to calculate the speech rate for each line in words per minute. For each character and the narrator, a grand mean of pitch across all lines was calculated. The grand mean values in hertz for dialogue and narration were then converted to a cents value relative to the conversational pitch of each participant using the formula $c=1200 \times \log _{2}\left(f_{2} / f_{1}\right)$, where $f_{1}$ is a participant's conversational pitch obtained using the Rainbow passage. Note that 100 cents is equal to one equaltempered semitone. For each character and the narrator, a grand mean of loudness in decibels across all lines was also calculated. The grand mean decibel values for dialogue and narration were then converted to a ratio value relative to the conversational loudness of each participant using the formula $x=2^{\wedge}\left(\mathrm{db}_{2}-\right.$ $\left.d_{1} / 10\right)$, where $d b_{1}$ is a participant's conversational loudness obtained using the Rainbow passage. This ratio showed how many times louder or quieter the 
M.Sc. Thesis - K. Matharu; McMaster University - Psychology, Neuroscience \& Behaviour

dialogue and narration were in comparison to the conversational loudness. To measure speech rate, the number of syllables for each line was calculated using an online automated syllable counter ("How Many Syllables", 2018) and corroborated by the researchers. For each line of the story, the number of syllables was divided by the duration of the line in minutes. The speech rate values were then compared to the conversational speech rate as a percentage increase or decrease. Lastly, timbre was measured using HNR. Line HNR values were compared to the conversational HNR using a comparative percent value either increasing or decreasing from the conversational HNR. Before examining the data, outliers—values outside of two standard deviations - were eliminated at the story level for each individual story.

In order to examine whether the produced pitch-levels of the various characters both within each story and across all stories conformed to our a priori predictions, we carried out a monotonic trend analysis (Matzke et al., 2010) to look at linear trends in pitch across characters. The significance of the monotonic trend was assessed using Mann-Kendall's tau, which tests if the dependent variable has an increasing or decreasing trend along the ordered independent variable, regardless of whether the trend is linear. Table 1 lists the characters in descending order of predicted vocal pitch. Table 2 lists all characters from all stories ordered in pitch from left to right across columns, and top to bottom within each column in increasing order of predicted vocal pitch. Correlations across all four vocal parameters using Spearman's rho were measured. A linear mixed-effects (LME) 
M.Sc. Thesis - K. Matharu; McMaster University - Psychology, Neuroscience \& Behaviour

regression model from the Ime4 package in $\mathrm{R}$ (Bates, Maechler, Bolker, \& Walker, 2015; R Core Team, 2013) was used to determine if participants created distinguishable vocal parameters for the various characters and if actors and nonactors portrayed the characters differently. A three-way LME was run for participant gender, the gender of the story characters, and acting experience.

\begin{tabular}{|c|c|c|c|c|c|c|}
\hline Level & $\begin{array}{c}1 \\
\text { Narrators }\end{array}$ & $\begin{array}{c}2 \\
\text { Lowest Adult } \\
\text { Male } \\
\text { Characters }\end{array}$ & $\begin{array}{c}3 \\
\text { Secondary } \\
\text { Adult Male } \\
\text { Characters }\end{array}$ & $\begin{array}{c}4 \\
\text { Adult Female } \\
\text { Characters }\end{array}$ & $\begin{array}{c}5 \\
\text { Maidens - } \\
\text { Second } \\
\text { Highest } \\
\text { Characters }\end{array}$ & $\begin{array}{c}6 \\
\text { Children and } \\
\text { Senior } \\
\text { Female } \\
\text { Characters }\end{array}$ \\
\hline Character & $\begin{array}{l}\text { - Narrator } \\
\text { (GTB, JB, } \\
\text { LRRH, RR) }\end{array}$ & $\begin{array}{l}\text { - Father Bear } \\
\text { (GTB) } \\
\text { - Bear (RR) } \\
\text { - Giant (JB) } \\
\text { - Wolf } \\
\text { (LRRH) }\end{array}$ & $\begin{array}{l}\text { - Woodcutter } \\
\text { (LRRH) } \\
\text { - Strange } \\
\text { Man (JB) } \\
\text { - Bear as } \\
\text { Prince (RR) }\end{array}$ & $\begin{array}{l}\text { - Giant's Wife } \\
\text { (JB) } \\
\text { - Mother (RR) } \\
\text { - Mother } \\
\text { (LRRH) } \\
\text { - Mother (JB) } \\
\text { - Mother Bear } \\
\text { (GTB) }\end{array}$ & $\begin{array}{l}\text { - Goldilocks } \\
\text { (GTB) } \\
\text { - Rose Red } \\
\text { (RR) } \\
\text { - Little Red } \\
\text { Riding Hood } \\
\text { (LRRH) }\end{array}$ & $\begin{array}{l}\text { - Jack (JB) } \\
\text { - } \\
\text { Grandmother } \\
\text { (LRRH) } \\
\text { - Wolf as } \\
\text { Grandmother } \\
\text { (LRRH) } \\
\text { - Little Girl } \\
\text { (RR) } \\
\text { - Baby Bear } \\
\text { (GTB) }\end{array}$ \\
\hline
\end{tabular}

Table 2. Ordering of all characters across all four stories based on age, gender, and species. Abbreviations: GTB, Goldilocks and the Three Bears; JB, Jack and the Beanstalk; LRRH, Little Red Riding Hood; RR, Rose Red.

\section{Results}

\section{Monotonic Trend Analysis}

In order to test the linear pitch predictions for the characters, as specified in Table 1, we ran monotonic trend analyses, both for the combination of all 20 characters across the four fairy tales (which we call the FULL analysis; Figure 1) and for each of the four stories individually (Figure 2). The results reported here 
M.Sc. Thesis - K. Matharu; McMaster University - Psychology, Neuroscience \& Behaviour

are for the actors and non-actors combined; the comparison between actors and non-actors will be presented below in the context of the LME analyses. All monotonic trend analyses were highly significant using Mann-Kendall's tau statistic: FULL: tau=0.246, $\mathrm{p}<0.001$; GTB: tau=0.450, $\mathrm{p}<0.001$; JB: tau=0.340, $p<0.001$; LRRH: tau=0.313, $p<0.001$; and $R R$ (tau $=0.532, p<0.001)$. These results indicate that participants produced changes in vocal pitch that conformed with our a priori predictions based on the gender, age, and species of the characters. The narrator voice was shown to be higher than the conversational voice by more than two semitones, suggesting that speakers used a type of performance voice for the narrator that was different from their conversational voice. In addition, every character was shown to have a higher pitch than the narrator (and thus the conversational voice as well), even characters such as the Giant in JB and the Wolf in LRRH, who, as males, would be assumed to have low-pitched voices. Monotonic trend analyses were also run for the three other vocal parameters using the same ordering as for pitch, although we did not have the same level of confidence in these predictions as we did for pitch. Significant monotonic trends (all $p<0.001$ ) were found for: loudness for FULL, GTB, LRRH, and RR; timbre for FULL and all four stories; and speech rate for GTB and JB, with a weaker trend seen for GTB than for other the stories and other variables. 
M.Sc. Thesis - K. Matharu; McMaster University - Psychology, Neuroscience \& Behaviour

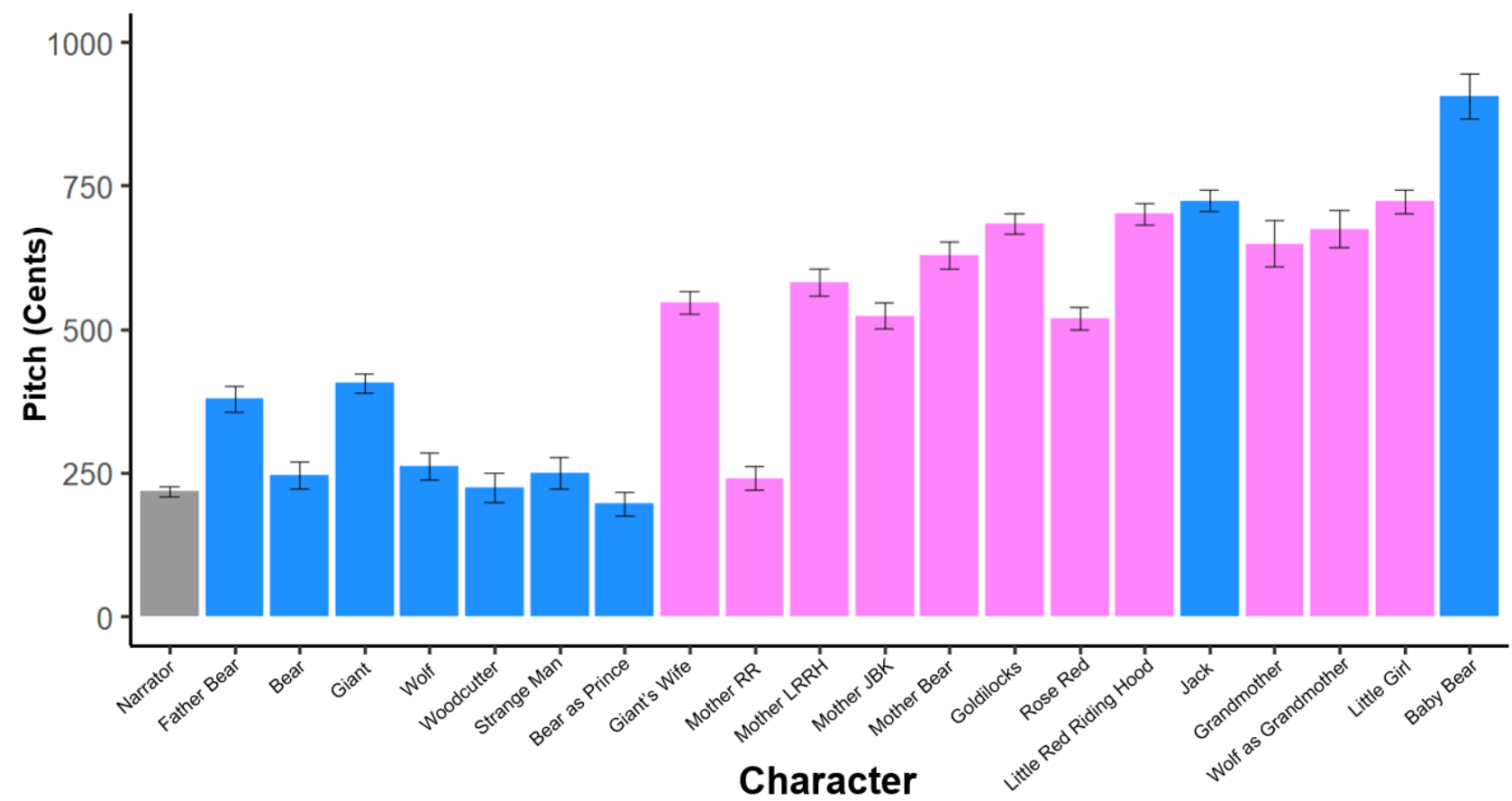

Figure 1. Mean pitch values for every character across all four stories, ordered from lowest to highest predicted pitch. Narrators are labelled in grey, male characters in blue, and female characters in pink. The narrators for all four stories have been compiled into one narrator value. The $y$ axis shows the pitch as an increase in cents relative to the conversational pitch. The results shown here are for the combination of the actors and non-actors. Each bar is the mean value. Error bars are standard errors of the mean. 
M.Sc. Thesis - K. Matharu; McMaster University - Psychology, Neuroscience \& Behaviour

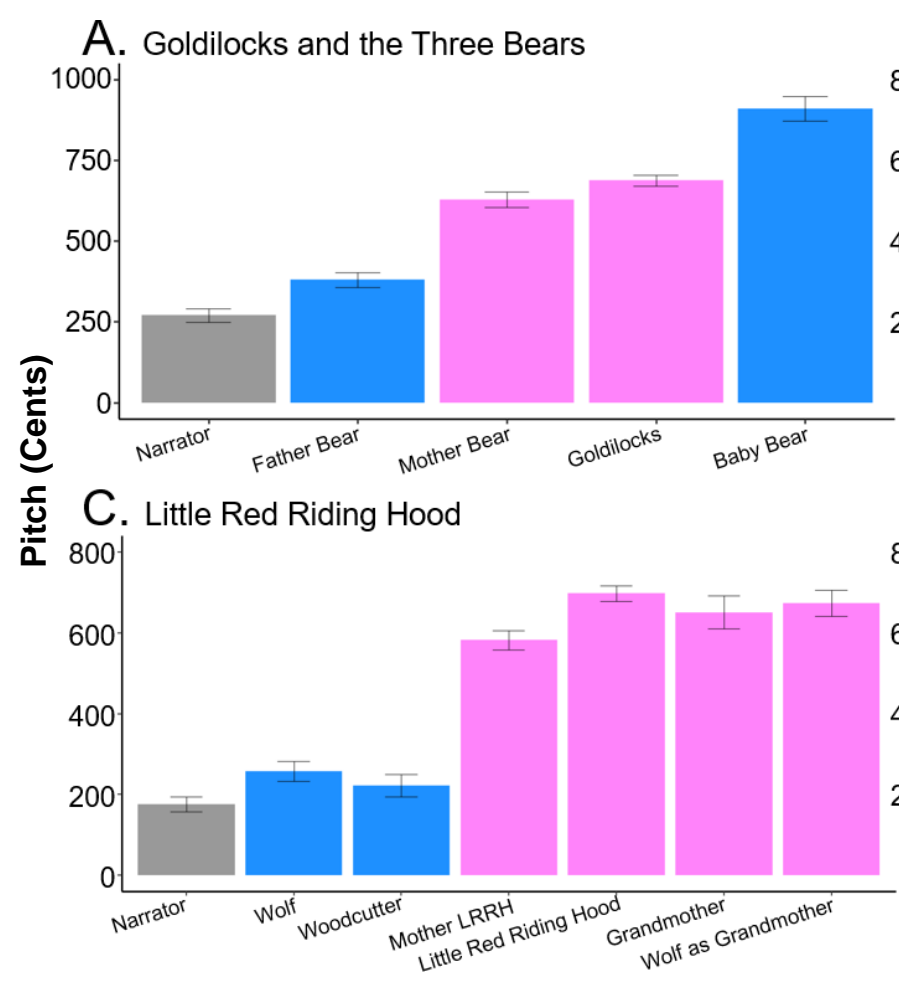

Character

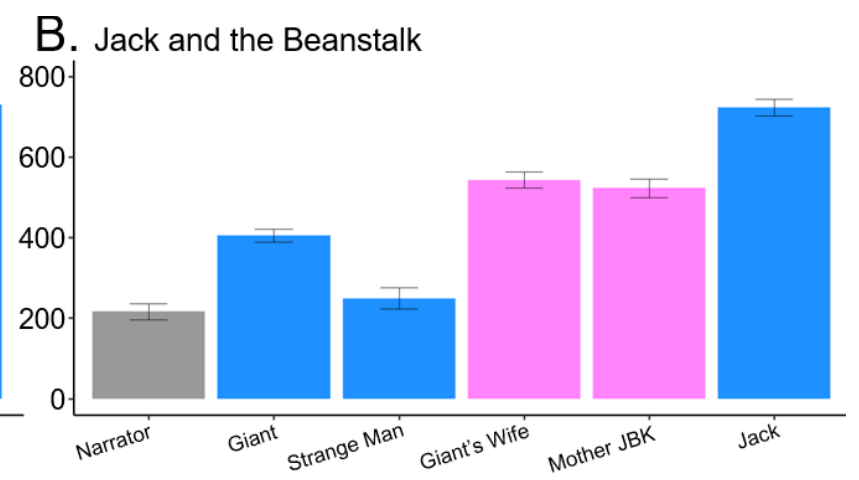

D. Rose Red

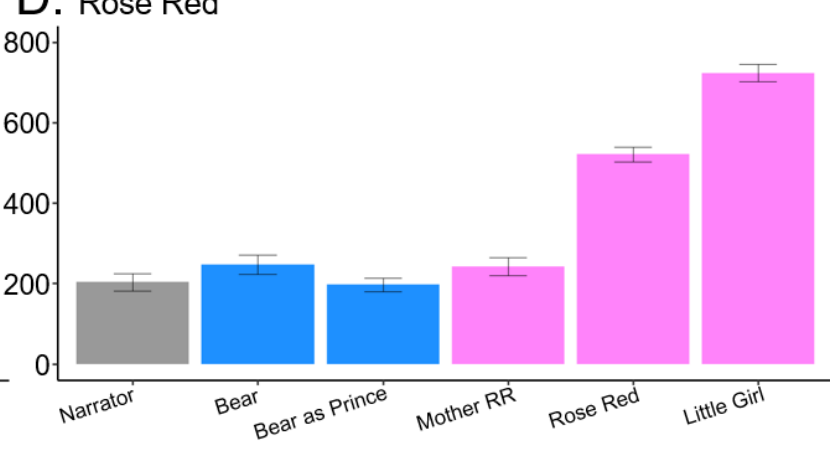

Character

Figure 2. Mean pitch values for every character within each of the four stories, ordered from lowest to highest predicted pitch. Narrators are labelled in grey, male characters in blue, and female characters in pink. The $y$ axis shows the pitch as an increase in cents relative to the conversational pitch. The results shown here are for the combination of the actors and non-actors. Each bar is the mean value. Error bars are standard errors of the mean.

\section{Correlations}

Most of the vocal parameters were found to be correlated with one another (see Table 3). This accounts, in part, for the significant monotonic-trend values found for the three exploratory variables of loudness, timbre, and speech rate when using the predictive character ordering based on pitch. All variables showed significant correlations with one another, except for the correlation between timbre and speech rate. Pitch, loudness, and timbre showed the highest correlations with one another. The strong correlation between pitch and loudness conforms with 
M.Sc. Thesis - K. Matharu; McMaster University - Psychology, Neuroscience \& Behaviour

similar results found in the literature on vocal emotion (Gramming et al., 1988) and the portrayal of stock characters by professional actors (Berry \& Brown, 2019).

\begin{tabular}{|c|c|c|c|c|}
\hline Pitch & Pitch & Loudness & Timbre & Speech Rate \\
\hline Loudness & $\begin{array}{c}\text { rho }=0.511 \\
p<0.001\end{array}$ & 1 & & \\
\hline Timbre & $\begin{array}{c}r h o=0.420 \\
p<0.001\end{array}$ & $\begin{array}{c}\text { rho }=0.436 \\
p<0.001\end{array}$ & 1 & \\
\hline $\begin{array}{c}\text { Speech } \\
\text { Rate }\end{array}$ & $\begin{array}{c}\text { rho }=-0.167 \\
p<0.001\end{array}$ & $\begin{array}{c}\text { rho }=-0.063 \\
p<0.001\end{array}$ & $\begin{array}{c}\text { rho }=-0.003 \\
p=0.865\end{array}$ & \\
\hline
\end{tabular}

Table 3. Correlations between the four vocal parameters.

\section{Effect of Acting Experience}

The previous analyses combined the actors and non-actors, and so we now use between-subject LME models to compare the two groups of participants, while including character as a within-subject factor. Figures 3 and 4 show similar analyses for pitch to those in Figures 1 and 2, except that the results are now broken down by acting experience. Consistent with the monotonic trend analyses, there was a significant main effect of character, indicative of the differentiation of characters using pitch. This was seen for FULL $(F=122, p<0.001)$ and for each of the four stories individually: GTB $(F=135, p<0.001), J B(F=100, p<0.001)$, LRRH $(F=113, p<0.001)$, and $R R(F=139, p<0.001)$. Moreover, there was a significant 
M.Sc. Thesis - K. Matharu; McMaster University - Psychology, Neuroscience \& Behaviour

main effect of acting experience. This was seen for FULL ( $F=14.8, p<0.001)$ and for each of the four stories: GTB $(F=7.38, p<0.01)$, JB $(F=8.09, p<0.01)$, LRRH $(F=14.1, p<0.001)$, and $R R(F=12.7, p<0.001)$. The actors portrayed characters with a higher pitch, on average, than the non-actors. However, this effect showed a significant interaction with character (see Figures 3 and 4). For the lower-pitched characters, the actors and non-actors portrayed the characters in a similar manner, but for the higher-pitched characters, the actors portrayed the characters with relatively higher pitch than the non-actors. In other words, the actors expanded their pitch range for the high-pitched characters more so than did the non-actors. For the highest produced characters, this amounted to a difference of about 750 cents (7.5 semitones). This experience-by-character interaction was significant for FULL ( $F=19.4, p<0.001)$, as well as for each of the four stories: GTB $(F=18.1$, $\mathrm{p}<0.001)$, JB $(\mathrm{F}=17.1, \mathrm{p}<0.001)$, LRRH $(\mathrm{F}=22.9, \mathrm{p}<0.001)$, and $\mathrm{RR}(\mathrm{F}=21.5$, $\mathrm{p}<0.001)$. 
M.Sc. Thesis - K. Matharu; McMaster University - Psychology, Neuroscience \& Behaviour

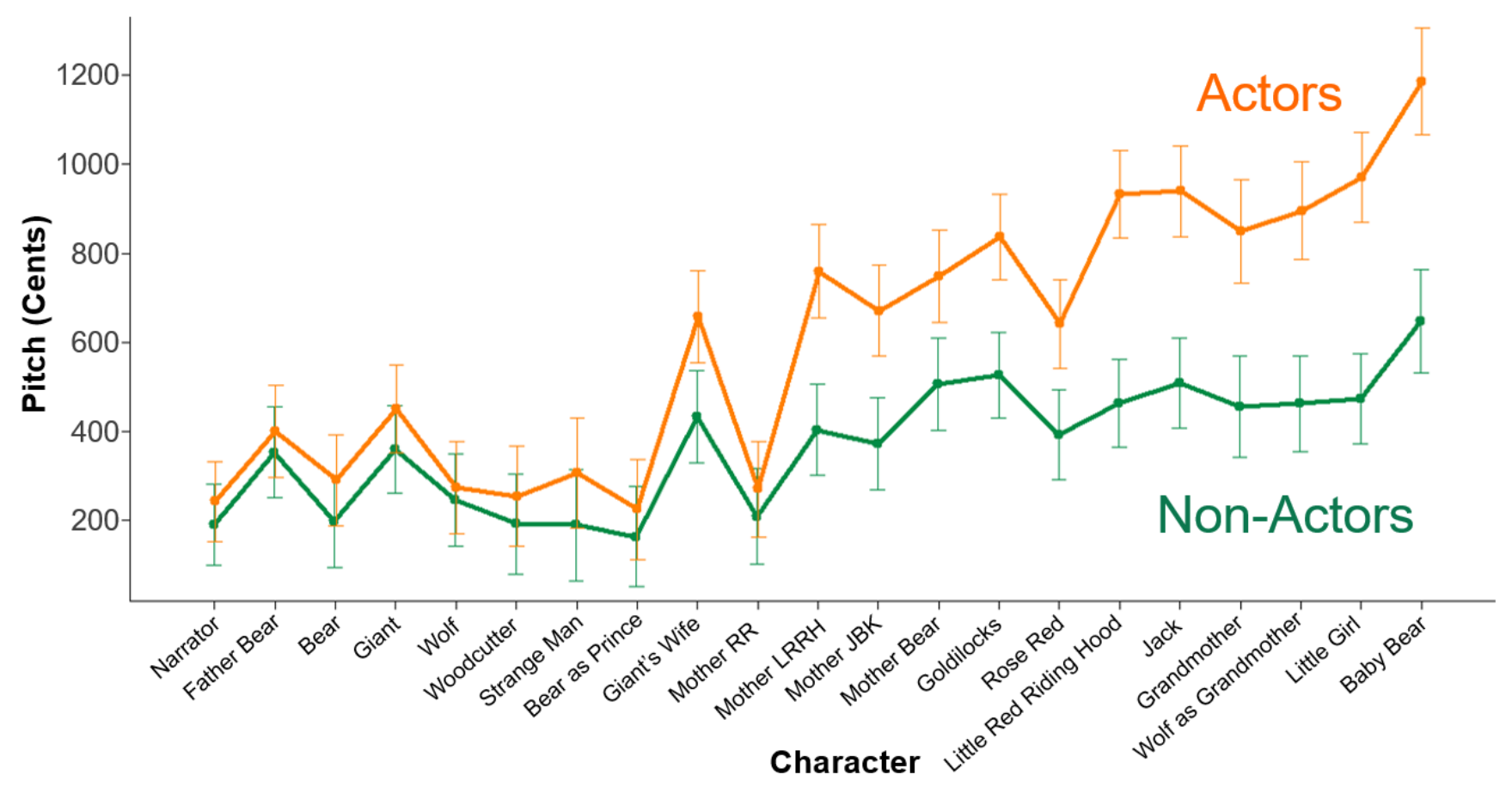

Figure 3. Mean pitch as a function of acting experience across all characters from all stories. The narrator has been compiled from all four stories. The $y$ axis shows the pitch as an increase in cents relative to the conversational pitch. The characters are ordered with regard to pitch predictions exactly as in Figure 1. Each value is the mean value. Error bars are standard errors of the mean. 
M.Sc. Thesis - K. Matharu; McMaster University - Psychology, Neuroscience \& Behaviour

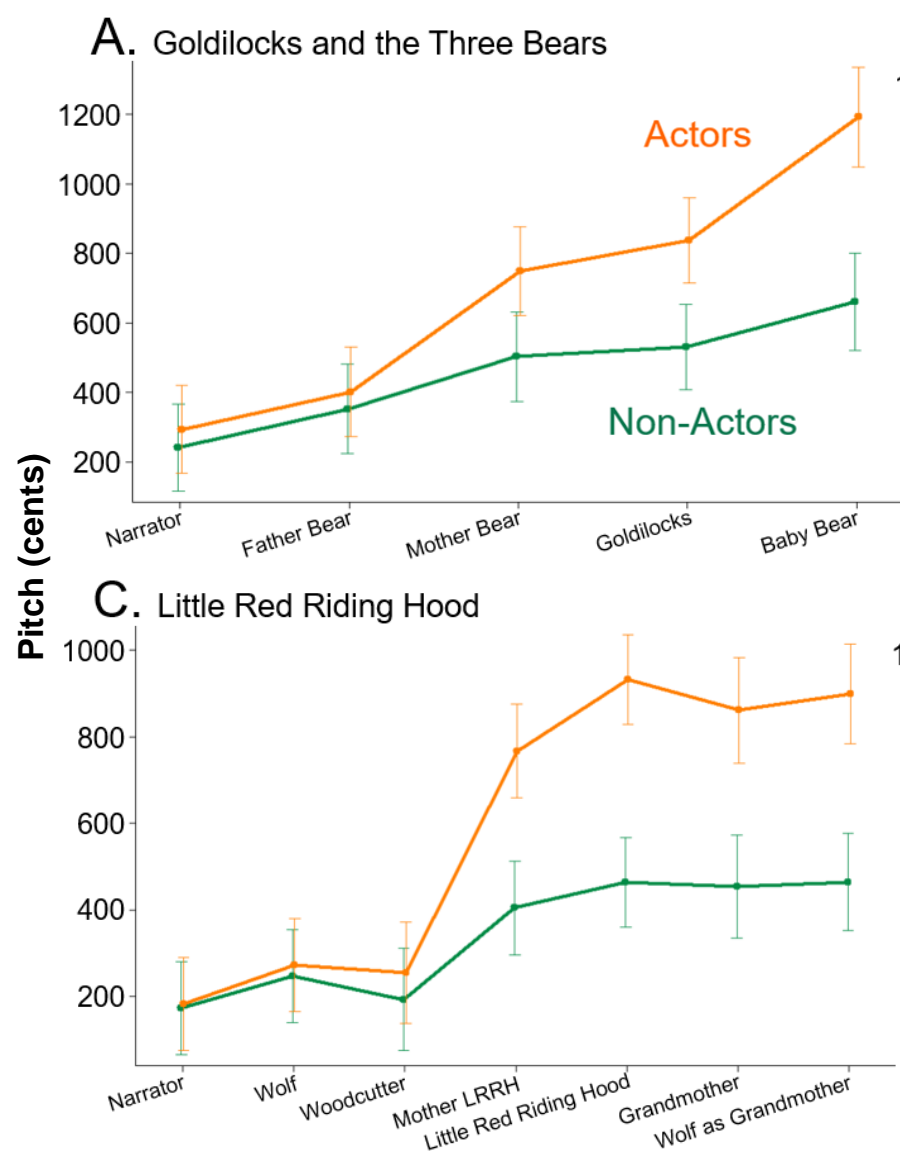

Character
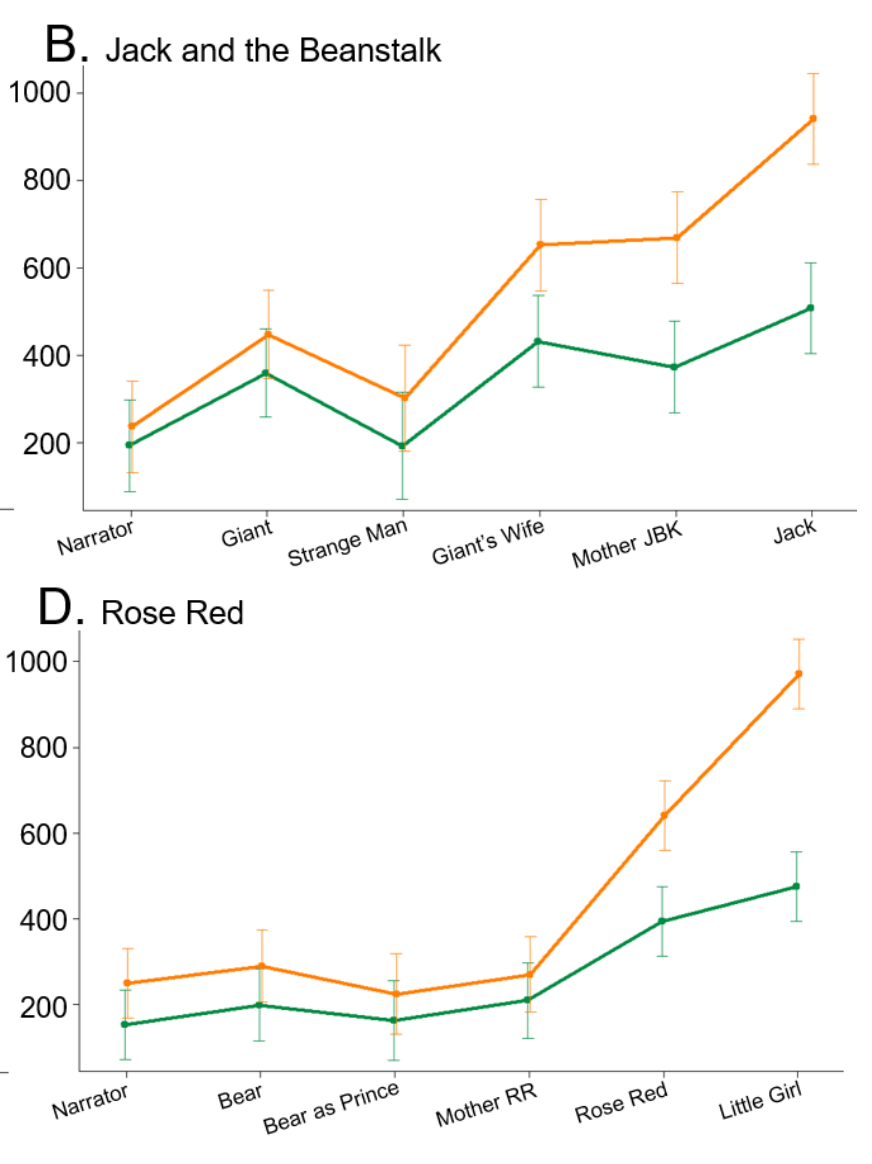

Character

Figure 4. Mean pitch as a function of acting experience for each of the four stories. The $y$ axis shows the pitch as an increase in cents relative to the conversational pitch. The characters are ordered with regard to pitch predictions exactly as in Figure 2. Each value is the mean value. Error bars are standard errors of the mean.

Looking now at the exploratory variables, the vocal parameters of loudness and timbre displayed a significant main effect of character and an interaction between character and acting experience for FULL and all four stories $(p<0.001$ for all analyses, except for the timbre value for the interaction between character and acting experience for Rose Red, where $\mathrm{p}=0.016)$. The patterns for both variables were similar to those for pitch, with higher-pitched characters being generally louder and having clearer timbre than lower-pitch characters. Low-pitched, 
M.Sc. Thesis - K. Matharu; McMaster University - Psychology, Neuroscience \& Behaviour

dominant male characters, like the Giant and Father Bear, showed a higher pitch than expected during portrayal. However, both of these characters were also portrayed more loudly, which may lead to a higher pitch during reading. Speech rate showed a different type of pattern (Figure 5). The most important finding was a significant main effect of acting experience for FULL and all four of the stories ( $p<0.001$ for FULL, JB, and LRRH; and $p<0.01$ for GTB and RR). Actors overall spoke more slowly than did non-actors, both when portraying the characters and when performing the narrator lines. In addition to the main effect of experience, there was a main effect of character on speech rate for FULL and for the four stories $(p<0.001)$. However, the zigzag pattern in Figure 5 indicates that it is not easy to create any generalizations regarding which characters tended to be portrayed more slowly versus more quickly. 
M.Sc. Thesis - K. Matharu; McMaster University - Psychology, Neuroscience \& Behaviour

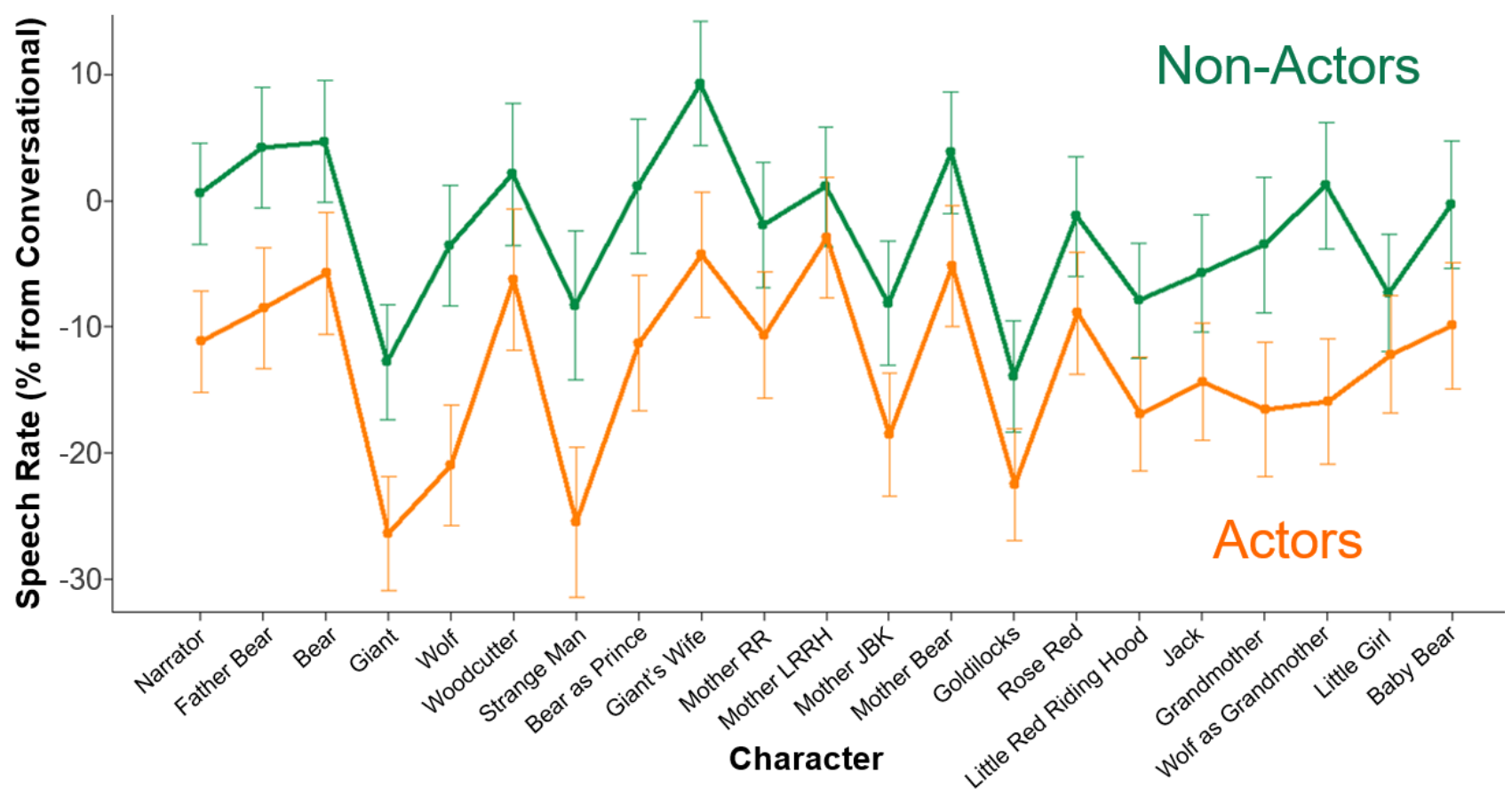

Figure 5. Effect of acting experience and character on mean speech rate across all characters from all stories. The narrator has been compiled from all four stories. The $y$ axis shows the speech rate as a percentage change from the conversational rate. Negative percentage values indicate a slower speech rate for a character compared to a participant's conversational speech rate. The characters are ordered with regard to pitch predictions exactly as in Figure 1. Each value is the mean value. Error bars are standard errors of the mean.

\section{Effects of Participant Gender and Character Gender}

The last issue to be looked at statistically is an LME analysis of character gender and participant gender for pitch. Do male and female participants produce comparable portrayals of male and female characters? Based on our predictive pitch scheme for characters (Table 1), we predicted that female characters would be produced higher than male characters, a prediction that was borne out for FULL $(F=310, p<0.001)$ and three of the four individual stories: GTB $(F=21.1, p<0.001)$, LRRH $(F=403, p<0.001)$, and $R R(F=194, p<0.001)$. With respect to participant gender, we had no a priori predictions. We observed no significant effect here, except for JB, for which male participants portrayed the characters higher (relative 
M.Sc. Thesis - K. Matharu; McMaster University - Psychology, Neuroscience \& Behaviour

to their conversational voice) than did female participants $(F=5.91, p=0.02)$. Other stories showed a similar, but non-significant, trend for males to produce higherpitched portrayals (relative to their conversational pitch) than females. There was no interaction between character gender and participant gender. For completeness, we mention again the interaction between experience and gender, shown in Figures 3 and 4, in which actors diverged from non-actors mainly for the high-pitched characters, which were mainly female characters but also included juvenile males.

\section{Pitch Production Across the Stories}

As a final analysis, we present pitch timeline graphs in Figures 6 and 7 for each story, showing the complete sequencing of the dialogue lines for each character in each story, in addition to select lines of narration (see the Methods section for a description of how the narrator lines were selected for each story). Each individual character is shown by means of a connected line running through the story. While no statistics are used here, the analysis gives a qualitative indication of the extent to which participants were consistent in producing the pitch of specific characters over the course of a story. Two major findings emerge from this analysis. First, the relatively flat profile for each individual character demonstrates that the character portrayals within each story were performed in a reliable manner, even by the non-actors. In other words, even though participants were using different pitches to represent different characters and were alternating between characters during many sections of dialogue, they tended to reliably return 
M.Sc. Thesis - K. Matharu; McMaster University - Psychology, Neuroscience \& Behaviour

to the same general pitch when portraying specific characters. Exceptions were seen in high-pitched female characters like Goldilocks. Goldilocks is unique among all of characters in the stories in that she does not physically interact with other characters or engage in dialogue with them; all of her lines are monologic. In addition, her lines are organized into groups of three in which she rejects the first two items of a category (e.g., porridge), but is pleased by the third one. Both of these factors might have contributed to the less-reliable pattern for Goldilocks compared to the other characters, who tended to have much more reliable pitch patterns across the stories. 
M.Sc. Thesis - K. Matharu; McMaster University - Psychology, Neuroscience \& Behaviour
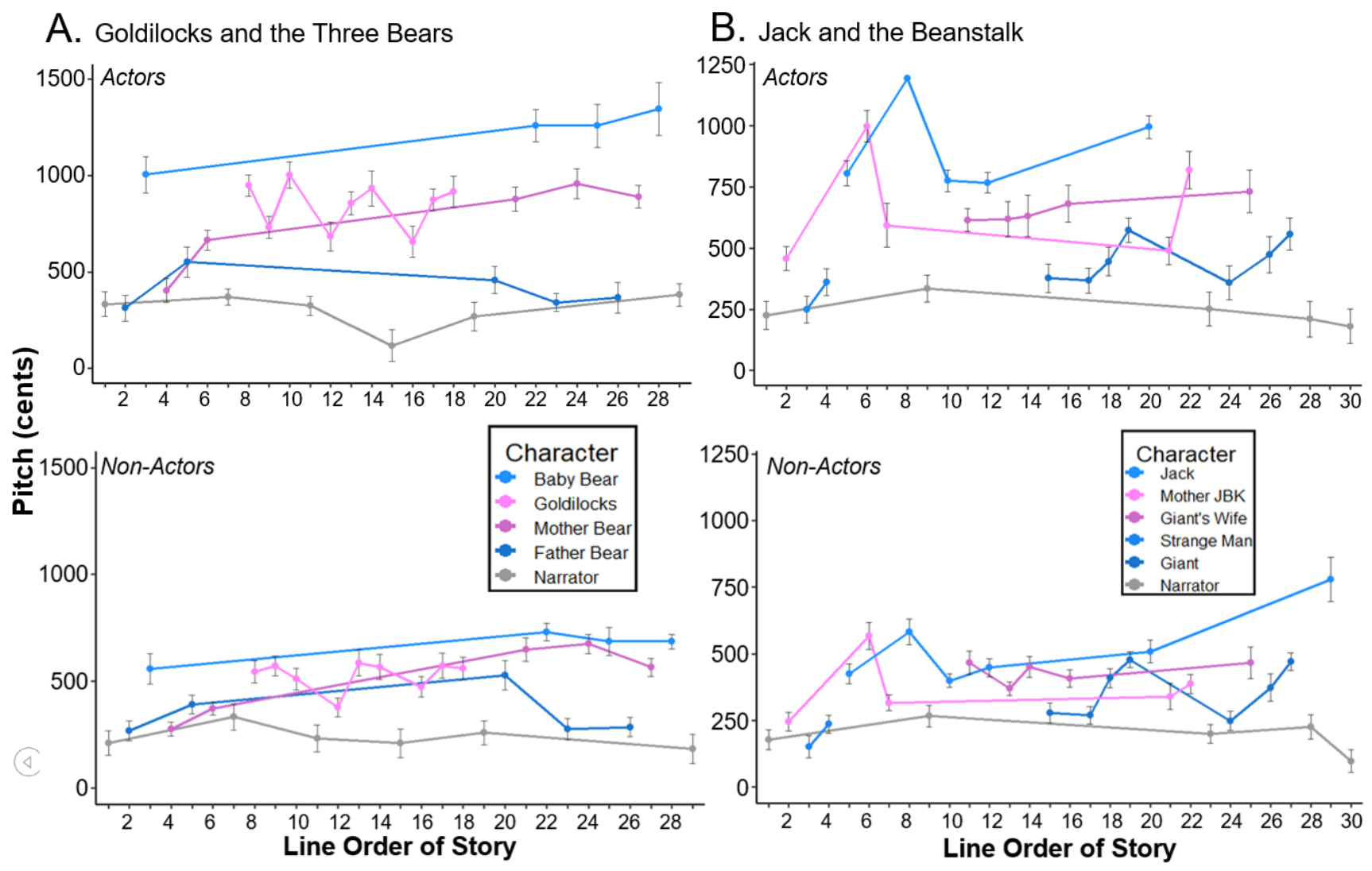

Figure 6. Mean pitch timeline graphs for the two participant groups for Goldilocks and the Three Bears and Jack and the Beanstalk. Narrators are labelled in grey, male characters in blue, and female characters in pink. The $y$ axis shows the pitch as an increase in cents relative to the conversational pitch. The $x$ axis shows the sequentially ordered lines throughout the story, where each point applies to one line of dialogue for one character or a line by the narrator. Only lines included in the analysis are included in the timeline graph. Hence, the narrator only consists of 5-6 lines for each story. Each value is the mean value. Error bars are standard errors of the mean. 
M.Sc. Thesis - K. Matharu; McMaster University - Psychology, Neuroscience \& Behaviour

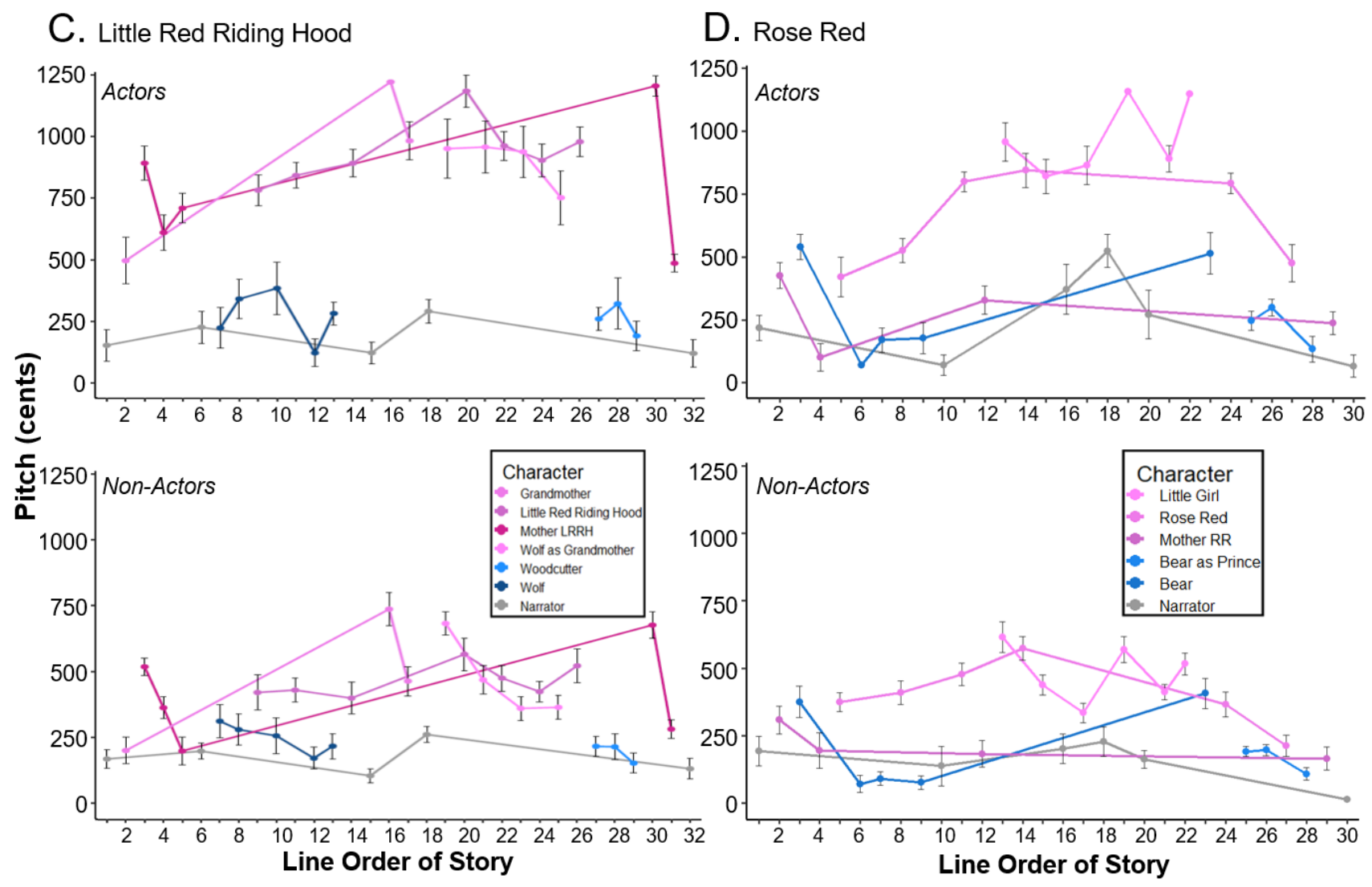

Figure 7. Mean pitch timeline graphs for the two participant groups for Little Red Riding Hood and Rose Red. Narrators are labelled in grey, male characters in blue, and female characters in pink. The $y$ axis shows the pitch as an increase in cents relative to the conversational pitch. The $x$ axis shows the sequentially ordered lines throughout the story, where each point applies to one line of dialogue for one character or a line by the narrator. Only lines included in the analysis are included in the timeline graph. Hence, the narrator only consists of 5-6 lines for each story. Each value is the mean value. Error bars are standard errors of the mean.

The second major finding was that actors showed a much more expansive pitch profile than the non-actors (or alternatively that the non-actors were compressed compared to the actors), allowing for a much greater differentiation of the characters from one another. This same general pattern is visible in each of the four stories, where the characters are further spaced out from one another, compared to those same characters produced by the non-actors (Figures 6 and 7). The non-actors did not extend their vocal pitch much beyond 750 cents relative to 
M.Sc. Thesis - K. Matharu; McMaster University - Psychology, Neuroscience \& Behaviour

their conversational voice, whereas actors extended their pitch almost 1500 cents above their conversational pitch. This roughly 750 -cent difference represents over half an octave of pitch range used by the actors, but not the non-actors, when portraying high-pitched characters. Hence, actors more optimally differentiated characters from one another by recruiting a larger part of their vocal range for this purpose.

\section{Discussion}

In the current study, we explored whether the recitation of fairy tales can be considered as a simple form of acting. The study is the first to quantitatively investigate the prosodic correlates of the vocal portrayal of fictional characters. We found that both non-actors and actors employed modulations of vocal prosody, primarily pitch, to differentiate the 4-6 characters in each story. The monotonic trend analyses demonstrated that participants' pitch productions conformed with our predictions about relative pitch based on the gender, age, and species of the various characters in a story. In fact, this trend remained significant in the combined set of 20 characters across all four stories, as well as within each story individually. The LME analyses showed that participants created distinct depictions of all characters in all four stories. The pitch timelines revealed that participants did this quite consistently throughout a story, such that they returned to the same general pitch every time a character recurred in a story, much as a ventriloquist does when alternating between the self and the dummy character. 
M.Sc. Thesis - K. Matharu; McMaster University - Psychology, Neuroscience \& Behaviour

The group comparison between trained actors and non-actors demonstrated that actors produced a more exaggerated version of the non-actor prosodic results, most especially with regard to pitch and speech rate. Actors spoke slower than non-actors, and this effect occurred consistently across all the characters. However, the effect of acting experience on pitch interacted with character. While actors produced higher-pitched depictions than non-actors overall—employing about half an octave of additional pitch range-this effect was strongly amplified for the high-pitched characters compared with the low-pitched characters. Finally, participant gender had minimal effect on the results. Since all character portrayal measures were relative to the conversational values, existing sex differences were eliminated. Hence, this analysis shows that there is no difference in character portrayal across participant gender after removing vocal sex differences. Overall, the findings of this study support the contention that the mimesis that occurs during story reading is a fundamental form of character portrayal and thus acting.

\section{Character Portrayal}

The LME results showed that participants portrayed the characters of the stories systematically and distinctly. Both within and across all four stories, protoacting behavior conformed with the pitch predictions established based on the age, gender, and species of the fairy tale characters. The inclusion of Rose Red to our stimulus set ensured that character portrayal was not driven exclusively by narrative familiarity. The monotonic trend and LME analyses showed that 
M.Sc. Thesis - K. Matharu; McMaster University - Psychology, Neuroscience \& Behaviour

participants portrayed the characters from Rose Red as they did in other fairy tales. Hence, the vocal changes used to portray characters did not arise from previouslyheard renditions of the characters, but from the features of the characters themselves, principally their age, gender, and species.

Previous prosodic analyses of character portrayal have reported either qualitative results alone or acoustic analyses with little quantitative detail. Doukhan et al. (2011) categorized story characters according to age, gender, and species, but did not provide detailed results about how each character was vocally portrayed. Similar to Doukhan et al. (2011), we found that male bear characters were portrayed with low pitches. The characters portrayed with the lowest pitch were adult male characters. Also similar to Doukhan et al. (2011), we found that child characters were generally portrayed with the highest pitches. While Doukhan et al. (2011) did not specify any elderly female characters in their analysis, we found that such characters were portrayed with high pitches, similar to adult females and child characters. For example, the characters of Grandmother and Wolf as Grandmother from Little Red Riding Hood were portrayed in the high pitch range.

With regard to character portrayal, we can distinguish "secondary" portrayal from "primary" portrayal. A primary portrayal would be a participant impersonating the Wolf from Little Red Riding Hood, while a secondary portrayal would be the person voicing the Wolf impersonating the Grandmother from that story. Little Red Riding Hood offered the sole instance of this phenomenon in our stimulus set. A 
M.Sc. Thesis - K. Matharu; McMaster University - Psychology, Neuroscience \& Behaviour

comparison of the pitch results for the Wolf, Grandmother, and Wolf as Grandmother demonstrated that the Wolf as Grandmother was portrayed with a voice most similar to the Grandmother's voice, and not as a male voice or as an intermediate portrayal between the two contributing characters. This demonstrates that the participant recognized that the Wolf was portraying the Grandmother and therefore adjusted his/her pitch to conform to this pretense within the story. Hence, the results suggest that a secondary character portrayal tracks the change in age, gender, and species of the secondarily portrayed character.

\section{Vocal Registers}

The monotonic trend analyses were able to reveal the overall patterns of portrayal when all the characters were organized by age, gender, and species. In addition, the timeline plots qualitatively demonstrated the reliability of each of the portrayals across the extent of a single story. The best example of this reliability was seen in the actors' portrayals of the characters from Goldilocks and the Three Bears, where each character had a timeline that showed minimal deviation, even in the case of Goldilocks, who showed the most variability in pitch. Interestingly, we observed that participants' use of pitch for character portrayal did not descend below their habitual pitch, even when impersonating adult male characters or villainous characters like the Wolf in Little Red Riding Hood or the Giant in Jack and the Beanstalk. Hence, all narration and character portrayal occurred above the habitual pitch. This phenomenon may be explained, in part, by the limited pitch space that exists below the habitual pitch, compared to above it. Participants 
M.Sc. Thesis - K. Matharu; McMaster University - Psychology, Neuroscience \& Behaviour

seemed to employ loudness to overcome the pitch limitations of the lower vocal range when conveying the dominance of the male characters (data not shown). Our quantification of both the magnitude and directionality of the prosodic changes for each of the characters improves upon previous work on quotation that merely has indicated whether a prosodic change occurred, but without providing quantitative details.

In examining the overall patterns of character portrayal across both the actors and the non-actors, we observed a hierarchical layering of sub-ranges during storytelling, as shown in the summary diagram in Figure 8. First, all participants, regardless of training, utilized a higher voice than their conversational speaking voice when reciting the narrator lines, averaging about 200 cents ( 2 semitones) higher than the conversational voice. We refer to this below as the expression of a "performance persona", since the narrator serves as the presenter during storytelling. Next, the non-actors accommodated the male and female characters within a sub-range that extended about 5 semitones above the narrator's pitch. This range corresponded roughly with the sub-range that the actors used exclusively for the adult male characters. In other words, the nonactors' full range was contained more or less within the actors' male-specific range. Finally, the actors had an additional sub-range that extended about 10 semitones above their male range for the adult female characters and the juvenile characters of both genders. This range was the main feature that distinguished the trained actors from the non-actors, the latter of whom spoke in a more compressed pitch 
M.Sc. Thesis - K. Matharu; McMaster University - Psychology, Neuroscience \& Behaviour

range. Hence, as we predicted, actors produced more-expansive renditions of the characters than did the non-actors, especially for the high-pitched characters.

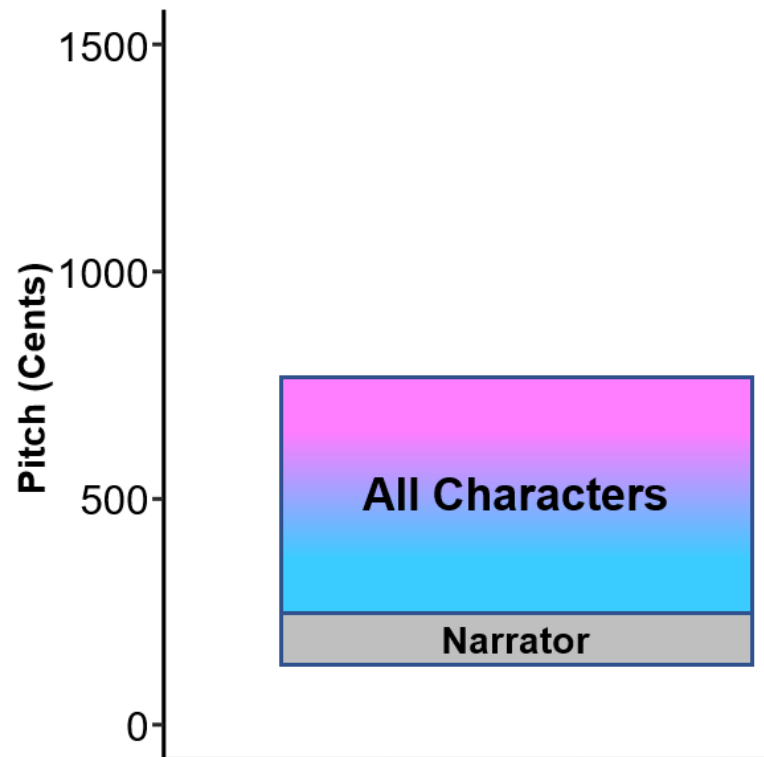

Non-Actors

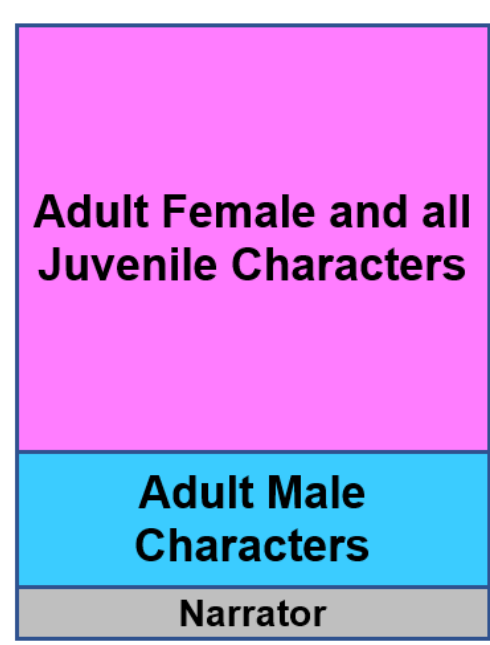

Actors

Figure 8. A schematic of the pitch results for the non-actors and actors. For both groups, the narrator was spoken roughly two semitones (200 cents) higher than the participant's habitual pitch, reflecting the expression of a performance persona. All of the fairy tale characters were spoken higher than the narrator's pitch for both groups. However, there was a significant divergence in pitch range between the two groups with respect to the characters. For the non-actors, all of the characters were contained in a roughly five semitone range beyond the narrator pitch, extending from around 250 cents to around 750 cents. The actors had an additional sub-range extending from around 550 cents to around 1500 cents that contained the higher-pitched characters, namely the adult females and the juvenile characters of both genders.

The observation that the narrator was performed around two semitones higher than the conversational voice comparably in non-actors and actors fits in with what Brown and Berry (2019) referred to as a performance persona. They described the performance persona as the presentation style that occurs "when a solo speaker is interacting with an attentive audience that is generally listening passively, rather than engaging in a dialogue. Such is the characteristic situation of caregiver-infant interaction, but is also the discursive arrangement of a seminar 
M.Sc. Thesis - K. Matharu; McMaster University - Psychology, Neuroscience \& Behaviour

speaker, a tour guide, the narrator of a story, and many other situations where one speaker plays a dominant role in an interaction with attentive, but typically silent, recipients." In agreement with the results of Berry and Brown (2019), we observed here that the narrator was higher, louder, and slower than the conversational voice, indicative of a presentational style meant to be demonstrational and to capture attention. This is the prosodic style of so-called motherese that caregivers use to interact with infants (Fernald, 1989; Greiser et al, 1988; Papoušek, Papoušek, \& Symmes, 1991; Reissland et al, 2003; Snow, 1977; Trainor et al, 2000; Whitehurst et al, 1988). Montano et al. (2013) argued that storytellers use a slower speech rate to focus the attention of the audience on the performance and ensure comprehension. The performance persona is an important consideration when studying the voice. Many previous studies have used a reading voice as a control condition when measuring the pitch used to portray other people or basic emotions (Doukhan et al., 2011; Montano et al., 2013; Revis et al., 2013; Stolarsky, 2015). However, a reciter's voice is not equivalent to their habitual baseline for everyday speech. Different contexts lead to different styles of reading, and this includes the vocal styles of motherese, news reading, storytelling, and the like (Doukhan et al, 2011; Snow, 1977; Theune et al, 2006; Trainor et al, 2000). Hence, our demonstration that the narrator's prosody reflects the operations of a performance mode of reading indicates that future studies of oral reading need to account for the performance persona when designing their experiments. 
M.Sc. Thesis - K. Matharu; McMaster University - Psychology, Neuroscience \& Behaviour

\section{Acting Experience}

The present experiment is the first study of character portrayal to directly compare trained actors and non-actors. The results showed that even people with no formal acting training at all have a strong tendency to distinguish the narrator voice from their own conversational speech and to reliably distinguish all of the characters from one another and from the narrator in a given story. This was demonstrated in both the monotonic trend analyses and in the pitch timeline graphs. From this, we argue that character portrayal during story reading is a basic form of acting, one that does not require explicit training. A study of neutral sentence reading by non-actors showed that non-emotional speech occupies a range of about 5 semitones above a person's habitual pitch (Chow \& Brown, 2018). Hence, the extension of the pitch range to 7.5 semitones (750 cents) above the habitual pitch for the non-actors in the present study is, by itself, a reflection of the impersonation of high-pitched characters. While the non-actors and actors shared a pitch range when depicting the adult male characters, the major effect of actor experience on the results was to expand the pitch range of the voice when depicting the adult female and all juvenile characters. Trained actors were able to add as much as 7.5 semitones of pitch space to their range beyond the non-actors. In addition, the actors also created slower depictions than the non-actors. These findings are consistent with previous work showing that actors produced emotional vocalizations that were rated as more extreme (Krahmer \& Swerts, 2008) and of 
M.Sc. Thesis - K. Matharu; McMaster University - Psychology, Neuroscience \& Behaviour

higher emotional intensity (Juslin, Laukka \& Banzinger, 2018) than those of nonactors.

\section{Gender Differences}

Both the gender of the participants and that of characters were relevant to this study. Since we normalized the vocal parameters of each participant to their conversational speaking voice, we were able to determine if males and females differentially portrayed the characters of the stories, despite the fact females speak about an octave (1200 cents) higher than males (Klatt \& Klatt, 1990). Regardless of their gender, the participants employed similar relative-pitch patterns in portraying fairy tale characters that varied based on age, gender, and species. While the participants portrayed female characters with a higher pitch, on average, than male characters, this portrayal did not vary based on the gender of the participants. Hence, it appears that the intrinsic features of the characters were the major determinants of the pitch productions, not the features of the participants. Overall, participant gender was a null factor in our study, whereas character gender was a strong predictor of vocal prosody.

\section{Limitations}

There are several important limitations of the present study. First, because fairy tales are a short format of literature, the brevity of these stories means that there are relatively few data points for each character across a story. Using novels, as did Montano et al. (2013), would allow us to test character effects across a longer stretch of narrative, including examining the consistency and emotional 
M.Sc. Thesis - K. Matharu; McMaster University - Psychology, Neuroscience \& Behaviour

variability of character portrayal. Another limitation of the study was the lack of an audience during the recitation task. Bavelas et al. (2014) reported that having an active listener during a conversational task facilitated the presenter's production of depictions, especially for gestures. Other studies have shown that the rate of depictions, including vocal portrayals, is higher in a dialogue condition-whether speaking to another individual face-to-face or over the phone-than in a monologue condition in which the participant is recounting a story on their own (Bavelas et al., 1995, 2000, 2008, 2014). Although participants in our study were asked to recite the stories as if reading to a child, we might have seen an even more accentuated style of depicting characters if one or more listeners had been present so as to create the impression of a performance.

Because we used published stories for our study, we had minimal control over the age, gender, and species of the characters within each story. In addition, there was only one example of secondary character portrayal in the study, namely the Wolf pretending to be the Grandmother in Little Red Riding Hood. Furthermore, the results of some of the vocal portrayals violated our predictions based on the character's age, gender, and/or species. For example, the Mother from Rose Red was portrayed with a lower pitch than the other mother characters in the other three stories. The other mothers were all similar in pitch and fell within the female subrange. However, the Mother from Rose Red was portrayed at about 250 cents above habitual, well within the male sub-range. We propose that this occurred because this mother was older than the other mothers. Rose Red is a maiden, 
M.Sc. Thesis - K. Matharu; McMaster University - Psychology, Neuroscience \& Behaviour

whereas the other mothers have young children, hence making them younger mothers than Rose Red's mother. Another character that showed unexpected results was the Giant from Jack and the Beanstalk, who was portrayed higher than expected. Because numerous studies have shown a robust positive correlation between pitch and loudness (Berry \& Brown, 2019; Gramming et al., 1988), we propose that the higher pitch for the Giant may have resulted from the higher loudness used when reciting his lines of dialogue.

The results of the present study can be easily extended to other contexts. A promising area of application is quotation in conversation, which is another common form of proto-acting (Brown, 2017). Instead of portraying fictional characters from well-known stories, people generally portray real individuals during improvised conversations. Future studies should be able to utilize the analysis methods of the present study to explore the depiction of people during conversational quotation. Pitch predictions can be made based on the gender and age of the quoted individuals. For example, it is likely that a person will use a higher pitch to depict his/her mother than father, or a child compared to an adult. This work also has applications in the recent popularity of audiobooks. The results presented here could be used to improve the quality of oral storytelling. In addition to real life storytellers, improvements could also be made in the development of TTS systems for storytelling speech. The systematic change in pitch used to portray characters, as well as the measures of the three exploratory variables, can help to further improve the verisimilitude of audiobook storytellers and TTS 
M.Sc. Thesis - K. Matharu; McMaster University - Psychology, Neuroscience \& Behaviour

systems. Finally, our results have a clear application to the craft of acting and to the character portrayal that occurs during dramatic acting, not to mention the related arts produced by impersonators and ventriloquists. While some acting methods emphasize the psychological component of acting and thereby downplay the gestural side (Stanislavski, 1936), many classic acting methods in world cultures are firmly rooted in the gestural mimicry of character archetypes (Diderot, 1773/1883; Kemp, 2012; Schechner, 2013). Hence, we can gain insight into the nature of gestural acting through the analysis of prosodic changes during character portrayal (Berry \& Brown, 2019).

\section{Conclusions}

In this first quantitative analysis of character portrayal, we found that both non-actors and actors modified their voices to distinctly portray all of the characters of a story. Actors' portrayals of the characters were more exaggerated than nonactors', and utilized a larger pitch range, specifically for the high-pitched (female and juvenile) characters. Character portrayals by all participants were consistent across a given story. Storytelling involved the expression of a "performance persona" such that the narrator and all characters were higher-pitched, louder, clearer, and slower than a participant's normal speaking voice. There was no effect of participant gender on the results, which suggests that it is the character's features, rather than the actor's, that determine the intonation used to portray a character. These results have application to other forms of proto-acting-such as quotation during conversation—as well as to professional acting, ventriloquism, 
M.Sc. Thesis - K. Matharu; McMaster University - Psychology, Neuroscience \& Behaviour

and impressionism. Overall, these results suggest that character portrayal during storytelling is perhaps the most fundamental form of acting in human life. 
M.Sc. Thesis - K. Matharu; McMaster University - Psychology, Neuroscience \& Behaviour

\section{References}

Anikin, A., \& Lima, C. F. (2018). Perceptual and acoustic differences between authentic and acted nonverbal emotional vocalizations. Quarterly Journal of Experimental Psychology, 71(3), 622-641. https://doi.org/10.1080/17470218.2016.1270976

Bates, D., Maechler, M., Bolker, B., \& Walker, S. (2015). Fitting linear mixedeffects models using Ime4. Journal of Statistical Software, 67(1), 1-48.

Bavelas, J. B., Chovil, N., Coated, L., \& Roe, L. (1995). Gestures specialized for dialogue. Personality and Social Psychology Bulletin, 21, 394-405.

Bavelas, J. B., Coates, L., \& Johnson, T. (2000). Listeners as co-narrators. Journal of Personality and Social Psychology, 79(6), 941-952. https://doi.org/10.1037/0022-3514.79.6.941

Bavelas, J., Gerwing, J., \& Healing, S. (2014). Effect of dialogue on demonstrations : Direct quotations, facial portrayals, hand gestures, and figurative references. Discourse Processes, 51, 619-655. https://doi.org/10.1080/0163853X.2014.883730

Bavelas, J., Gerwing, J., Sutton, C., \& Prevost, D. (2008). Gesturing on the telephone: Independent effects of dialogue and visibility. Journal of Memory and Language, 58(2), 495-520. https://doi.org/10.1016/j.jml.2007.02.004 
M.Sc. Thesis - K. Matharu; McMaster University - Psychology, Neuroscience \& Behaviour

Berry, M., \& Brown, S. (2019). Acting in action: Prosodic analysis of character portrayal during acting. Journal of Experimental Psychology: General, 148, 1407-1425. http://dx.doi.org/10.1037/xge0000624

Blackwell, N. L., Perlman, M., \& Fox Tree, J. E. (2015). Quotation as a multimodal construction. Journal of Pragmatics, 81, 1-7. https://doi.org/10.1016/j.pragma.2015.03.004

Boersma, P. (2001). Praat, a system for doing phonetics by computer. Glot International, 5(9-10), 314-345.

Bretherton, I. (1989). Pretense: The form and function of make-believe play. Developmental Review, 9, 383-401. https://doi.org/10.1016/02732297(89)90036-1

Brosch, T., Grandjean, D., Sander, D., \& Scherer K. R. (2008). Behold the voice of

wrath: Cross-modal modulation of visual attention by anger prosody. Cognition, 106(3), 1497-1503. https:// doi:10.1016/j.cognition.2007.05.011

Brown, S. (2017). Proto-acting as a new concept: Personal mimicry and the origins of role playing. Humanities, 6, 43. https://doi.org/10.3390/h6020043

Cartei, V., \& Reby, D. (2012). Acting gay: Male actors shift the frequency components of their voices towards female values when playing homosexual 
M.Sc. Thesis - K. Matharu; McMaster University - Psychology, Neuroscience \& Behaviour

characters. Journal of Nonverbal Behavior, 36, 79-93.

https://doi.org/10.1007/s10919-011-0123-4

Chow, I., \& Brown, S. (2018). A musical approach to speech melody. Frontiers in Psychology, 9(247), 1-17. https://doi.org/10.3389/fpsyg.2018.00247

Clark, H. H. (2016). Depicting as a method of communication. Psychological Review, 123(3), 324-347. https://doi.org/http://dx.doi.org/10.1037/rev0000026

Cohen, L. E. (2011). Bakhtin's carnival and pretend role play: A comparison of social contexts. American Journal of Play, 4(2), 176-203.

Diderot, D. (1883). The paradox of acting. (H. Irving, Trans.) London, UK: Chatto \& Windus. (Original work published 1773)

Doukhan, D., Rilliard, A., Rosset, S., Adda-Decker, M., \& D’Alessandro, C. (2011). Prosodic analysis of a corpus of tales. In Proceedings of the Annual Conference of the International Speech Communication Association, INTERSPEECH (pp. 3129-3132). Paris, France.

Doukhan, D., Rosset, S., Rilliard, A., Alessandro, C., \& Adda-decker, M. (2015). The GV-LEx corpus of tales in French. Language Resources and Evaluation, 49(3), 521-547. https://doi.org/10.1007/s10579-015-9306-7 
M.Sc. Thesis - K. Matharu; McMaster University - Psychology, Neuroscience \& Behaviour

Doukhan, D., Rosset, S., Rilliard, A., Alessandro, C., Decker, M. A., Cnrs, L., \& France, O. (2012). Text and speech corpora for text-to-speech synthesis of tales. In Proceedings of the 8th International Conference on Language Resources and Evaluation (pp. 1003-1010). Istanbul, Turkey.

Fairbanks, G. (1960). Voice and articulation drillbook. Philadelphia: Harper \& Row.

Fernald, A. (1989). Intonation and communicative intent in mothers' speech to infants: Is the melody the message? Child Development, 60(6), 1497-1510.

Foreman, M. (2005). Classic Fairy Tales. New York: Sterling Publishing.

Fujikawa, G. (2008). Fairy Tales and Fables. New York: Sterling Publishing. Goffman, E. (1959). The presentation of self in everyday life. New York: Anchor Books.

Gool, V. (1993). Van Gool's Jack and the Beanstalk. Toronto: Twin Books. Gramming, P., Sundberg, J., Ternstrom, S., Leanderson, R., \& Perkins, W. H. (1988).

Relationship between changes in voice pitch and loudness. Journal of Voice, 2(2), 118-126.

Grieser, D. L., \& Kuhl, P. K. (1988). Maternal speech to infants in a tonal language : Support for universal prosodic features in motherese. Developmental Psychology, 24(1), 14-20. 
M.Sc. Thesis - K. Matharu; McMaster University - Psychology, Neuroscience \& Behaviour

Guenther, L. (2015). Little Red Riding Hood. Retrieved July 05, 2016, from http://www.dltk-teach.com/rhymes/littlered/story.htm

Hirst, D. (2011). The analysis by synthesis of speech melody: From data to models.

Journal of Speech Sciences. 1(1), 55-83.

How Many Syllables. (2018). Retrieved from https://www.howmanysyllables.com/ Jackson, K. (1969). The golden book of 365 stories: A story for every day of the year.

New York: Western Publishing Company

Jurgens, R., Grass, A., Drolet, M., \& Fischer, J. (2015). Effect of acting experience on emotion expression and recognition in voice: Non-actors provide better stimuli than expected. Journal of Nonverbal Behavior, 39, 195-214. https://doi.org/10.1007/s10919-015-0209-5

Juslin, P. N., \& Laukka, P. (2003). Communication of emotions in vocal expression and music performance: Different channels, same code? Psychological Bulletin, 129(5), 770-814. https://doi.org/10.1037/00332909.129.5.770

Juslin, P. N., Laukka, P., \& Banziger, T. (2018). The mirror to our soul? Comparisons of spontaneous and posed vocal expression of emotion. Journal of Nonverbal Behavior, 42, 1-40. https://doi.org/https://doi.org/10.1007/s10919-017-0268-x 
M.Sc. Thesis - K. Matharu; McMaster University - Psychology, Neuroscience \& Behaviour

Kemp, R. (2012). Embodied acting: What neuroscience tells us about performance. London: Routledge.

Klatt, D. H., \& Klatt, L. C. (1990). Analysis, synthesis, and perception of voice quality variations among female and male talkers (Vol. 87). https://doi.org/10.1121/1.398894

Krahmer, E., \& Swerts, M. (2008). On the role of acting skills for the collection of simulated emotional speech. In Proceedings of the International Conference on Spoken Language Processing (Interspeech 2008) (pp. 261-264). Brisbane, Interspeech.

Landy, R. J. (1993). Persona and performance: The meaning of role in drama, therapy,

and everyday life. New York: Guilford.

Matzke, B. D., Wilson, J. E., Nuffer, L. L., Dowson, S. T., Hathaway, J. E., Hassig, N. L.,

... McKenna, S. (2010). Visual Sample Plan Version 6.0 User's Guide. PNNL-19915, Pacific Northwest National Laboratory, Richland, Washington.

Montaño, R., Alías, F., \& Ferrer, J. (2013). Prosodic analysis of storytelling discourse modes and narrative situations oriented to Text-to-Speech 
M.Sc. Thesis - K. Matharu; McMaster University - Psychology, Neuroscience \& Behaviour

synthesis. 8th ISCA Workshop on Speech Synthesis, 171-176.

https://doi.org/10.1038/ncomms4105

Papoušek, M., Papoušek, H., \& Symmes, D. (1991). The meanings of melodies in

motherese in tone and stress languages. Infant Behavior and

Development, 14(4), 415-440.

Plato (380 BCE/1968). The republic. Translated by Allan Bloom. New York: Basic Books.

R Core Team (2013). R: A language and environment for statistical computing. $R$ Foundation for Statistical Computing, Vienna, Austria. URL http://www.Rproject.org/.

Reissland, N., Shepherd, J., \& Herrera, E. (2003). The pitch of maternal voice: A comparison of mothers suffering from depressed mood and non-depressed mothers reading books to their infants. Journal of Child Psychology and Psychiatry, 44(2), 255-261. https://doi.org/10.1111/1469-7610.00118

Revis, J., De Looze, C., \& Giovanni, A. (2013). Vocal flexibility and prosodic strategies in a professional impersonator. Journal of Voice, 27(4), 524.e23524.e31. https://doi.org/10.1016/j.jvoice.2013.01.008

Sawyer, R. K. (1996). Role voicing, gender, and age in preschool play discourse. Discourse Processes, 22, 289-307. 
M.Sc. Thesis - K. Matharu; McMaster University - Psychology, Neuroscience \& Behaviour

Schechner, R. (2013). Performance studies: An introduction. 3rd ed. London: Routledge.

Shulman, D (2017). The presentation of self in contemporary social life. Thousand

Oaks: SAGE Publications.

Snedeker, J., \& Trueswell, J. (2003). Using prosody to avoid ambiguity: Effects of speaker awareness and referential context. Journal of Memory and Language, 48(1), 103-130.

Snow, C. (1977). Mothers' speech research: From input to interaction. In C. E. Snow \& C. A. Ferguson (Eds.), Talking to children (pp. 31-49). Cambridge: Cambridge University Press.

Stanislavski, C. (1936). An actor prepares. New York: Theater Arts Books.

Stec, K., Huiskes, M., Wieling, M., \& Redeker, G. (2017). Multimodal character viewpoint in quoted dialogue sequences. Glossa: $A$ Journal of General Linguistics, 2(1), 39. https://doi.org/10.5334/gjgl.255

Stolarski, L. (2015). Pitch patterns in vocal expression of "happiness" and "sadness" in the reading aloud of prose on the basis of selected audiobooks. Research in Language, 13(2), 141-162. https://doi.org/10.1515/rela-20150016 
M.Sc. Thesis - K. Matharu; McMaster University - Psychology, Neuroscience \& Behaviour

Teshigawara, M., \& Murano, E. Z. (2004). Articulatory correlates of voice qualities of good guys and bad guys in Japanese anime: An MRI study. In Proceedings of the International Conference on Spoken Language Processing (Interspeech 2004) (pp. 1249-1252). Jeju, Korea.

The Story of Goldilocks and the Three Bears. (2016). Retrieved July 05, 2016, from

http://www.dltk-teach.com/rhymes/goldilocks_story.htm

Theune, M., Meijs, K., Heylen, D., \& Ordelman, R. (2006). Generating expressive speech for storytelling applications. IEEE Transactions on Audio, Speech and Language Processing, 14(4), 1137-1144.

https://doi.org/10.1109/TASL.2006.876129

Trainor, L. J., Austin, C. M., \& Desjardins, N. (2000). Is infant-directed speech prosody a result of the vocal expression of emotion. Psychological Science, 11(3), 188-195.

Wade, E., \& Clark, H. H. (1993). Reproduction and demonstration in quotations. Journal of Memory and Language, 32(6), 805-819.

Whitehurst, G. J., Falco, F. L., Lonigan, C. J., Fischel, J. E., DeBaryshe, B. D., Valdez-Menchaca, M. C., \& Caulfield, M. (1988). Accelerating language development through picture book reading. Developmental Psychology, 24(4), 552-559. https://doi.org/10.1037/0012-1649.24.4.552 